\title{
Fiscal policy in good and bad times
}

Citation for published version (APA):

Candelon, B., \& Lieb, L. M. (2011). Fiscal policy in good and bad times. METEOR, Maastricht University School of Business and Economics. METEOR Research Memorandum No. 001 https://doi.org/10.26481/umamet.2011001

Document status and date:

Published: 01/01/2011

DOI:

10.26481/umamet.2011001

Document Version:

Publisher's PDF, also known as Version of record

\section{Please check the document version of this publication:}

- A submitted manuscript is the version of the article upon submission and before peer-review. There can be important differences between the submitted version and the official published version of record.

People interested in the research are advised to contact the author for the final version of the publication, or visit the DOI to the publisher's website.

- The final author version and the galley proof are versions of the publication after peer review.

- The final published version features the final layout of the paper including the volume, issue and page numbers.

Link to publication

\footnotetext{
General rights rights.

- You may freely distribute the URL identifying the publication in the public portal. please follow below link for the End User Agreement:

www.umlib.nl/taverne-license

Take down policy

If you believe that this document breaches copyright please contact us at:

repository@maastrichtuniversity.nl

providing details and we will investigate your claim.
}

Copyright and moral rights for the publications made accessible in the public portal are retained by the authors and/or other copyright owners and it is a condition of accessing publications that users recognise and abide by the legal requirements associated with these

- Users may download and print one copy of any publication from the public portal for the purpose of private study or research.

- You may not further distribute the material or use it for any profit-making activity or commercial gain

If the publication is distributed under the terms of Article $25 \mathrm{fa}$ of the Dutch Copyright Act, indicated by the "Taverne" license above, 


\section{Maastricht University}

Bertrand Candelon, Lenard Lieb

Fiscal Policy in Good and Bad Times

$\mathrm{RM} / 11 / 001$

\section{METEOR}

Maastricht University School of Business and Economics

Maastricht Research School of Economics

of Technology and Organization

P.O. Box 616

NL - 6200 MD Maastricht

The Netherlands 


\title{
Fiscal Policy in Good and Bad Times
}

\author{
Bertrand Candelon ${ }^{1}$ and Lenard Lieb ${ }^{2},{ }^{3}$
}

\begin{abstract}
Using a Threshold Vector Autoregression framework identified via sign restrictions, we answer three questions: First, are fiscal policy shocks regime-dependent? Second, which variables are governing the regime? Third, what are the effects of fiscal policies on the main macroeconomic variables in each of these states? The linearity hypothesis is strongly rejected, with the two detected regimes clearly identifiable as recession and boom phases. We find that fiscal policy shocks have a stronger impact in times of economic stress than in times of expansion, and that direct spending policies are more efficient than tax-cut policies in stabilizing the economy in the short-run.
\end{abstract}

J.E.L. Codes: E32

Keywords: Fiscal Policy; Nonlinearity; Threshold Vector Autoregression.

${ }^{1}$ Department of Economics, Maastricht University, School of Business and Economics, PoBOX 616, MD 6200, Maastricht, The Netherlands, Tel.: +31 43 3883442; fax: +31 43 3884864; E-mail address: b.candelon@maastrichtuniversity.nl (B. Candelon).

${ }^{2}$ Department of Economics, Maastricht University, School of Business and Economics, PoBOX 616, MD 6200, Maastricht, The Netherlands, Tel.: +31 43 3883653; fax: +31 43 3884864; E-mail address: l.lieb@maastrichtuniversity.nl (L. Lieb).

${ }^{3}$ The authors thank Marco Avarucci, Eric Beutner, and Mark Spiegel for discussions and advices. We also thank Harald Uhlig for valuable feedback and for supplying the data. We are grateful to comments received at internal seminars at the Universities of California at Santa Cruz, Orleans, Maastricht, and at the 2010 meeting of the Methods in International Finance Network (MIFN) in Jinan. Usual disclaimers apply. 


\section{Introduction}

The economic literature has always paid a particular attention to the evaluation the effects of different

fiscal policies in order to provide policymakers with the most efficient tool to stabilize economic activity.

In particular, the question whether a tax-cut policy stimulates real activity more than a government

spending shock has fueled years of discussion between Keynesian and classical economists. The interest

for such a problematic has been renewed with the current financial crisis. In front of a severe recession,

policymakers are trying to establish whether fiscal stimuli should remain similar to those implemented in

the pre-cris period or whether they should be specific to this recession period.

As the economy is often seen as a dynamic system driven by stochastic shocks, Vector Autoregressions

(VARs) have become a popular tool to empirically assess the economy's reaction to political decisions

(e.g. fiscal policy shocks). A key question for macroeconomists using VARs for policy analysis, consists

in identifying the underlying policy shock(s). The literature on the identification of fiscal policy shocks

provides basically two ways to identify a structural VAR (SVAR). The most established one, relies on

(theoretical) quantitative assumptions about the (long-run) reaction of some variables to a fiscal policy

shock, as for instance in Blanchard and Perotti (2002). A more recent approach incorporates qualitative

and quantitative information in order to identify policy shocks, which are identified by sign restrictions

or other prior information about the impulse responses. The recent paper of Mountford and Uhlig (2009)

constitute a perfect illustration of this approach: They build a 10 dimensional VAR, estimate it for the 
period $1955(I)-2000(I V)$ and then use sign restrictions to identify fiscal shocks as well as policy effects. ${ }^{4}$

Hence, they can confirm that a deficit-financed tax cut constitutes the best strategy to increase GDP compared to deficit-spending and balanced budget spending expansion.

The two papers mentioned above, as well as all similar studies (e.g. Burnside et al., 2004, Galí et al., 2007, or Romer and Romer, 2010), implicitly assume that the relative efficiency of fiscal policies does not vary over time and hence the VAR is linear. Nevertheless, in our opinion this assumption is particularly strong, as it is hard to believe that a particular fiscal shock will provide the same effect on activity whether the economy is in recession or in expansion, or if it is facing a severe financial crisis. Several studies confirm this intuition. Perotti (1999) provides a theoretical support for this fact using private consumption and showing that shocks to government revenues and, especially, expenditure have very different effects on private consumption in "good" and "bad" times. Similarly, Giavazzi et al. (2000) find nonlinearities in the response to fiscal policies, which depend on the size of the shock. ${ }^{5}$ Unfortunately, none of the latter studies has kept a VAR representation, while it constitutes a relevant framework to examine the propagation of a shock within a dynamic system, taking into account the transmission effect between variables. Their modeling choice is due to the difficulty of testing for nonlinearity in such a framework and identifying correctly the policy shocks.

This paper proposes to fill this gap using a nonlinear VECM à la Bec and Rahbek (2004) with stable co-integration relations but regime-dependent short-run dynamics. This framework allows us to test for

\footnotetext{
${ }^{4}$ Their VAR includes GDP, total government expenditure, total government revenue, interest rate, adjusted reserves, the producer price index for crude materials, the GDP deflator, private consumption, private non-residential investment, and real wages.

${ }^{5}$ The nonlinearity of the response is stronger for fiscal contractions than for expansions.
} 
the presence of regimes (via a Wald test for linearity), to estimate the threshold classifying the regimes, as well as the variables governing them. We use sign restriction to identify structural policy shocks and evaluate the effect via impulse response functions in each regime. Such a framework allows us to answer three questions: First, are fiscal policy shocks regime dependent? Second, which variables are governing the regime? Third, what are the effects of fiscal policies on the main macroeconomic variables in each of these states?

Anticipating on our results, it turns out that the hypothesis of linearity of the VECM parameters is strongly rejected, leading us to detect two regimes, identifiable clearly as recession and boom phases, respectively. Interestingly, the nonlinearity is not driven by stock market indices, but rather by business cycle stance. Analyzing the regime dependent impulse response functions, we observe that fiscal policy shocks have a stronger impact in times of economic stress than in times of expansion. Moreover, it turns out that direct spending policies are more efficient than tax-cut policies in stabilizing the economy in the short-run. Such a result tends to be in line with the prediction of New-Keynesian models.

The paper is organized as follows. Section 2 reviews the methodology that is implemented. Section 3 presents the results from the threshold-VECM and the regime identification, whereas Section 4 elaborates on the effects for a set of macroeconomic variables after identified fiscal policy shocks. Section 5 concludes. 


\section{Methodology}

\subsection{A Multivariate threshold model}

Following Tong (1990) and Tsay (1998), several papers stressed that macroeconomic dynamics (univariate or multivariate) may be nonlinear and in particular regime-specific. Indeed, it is likely that the short-run impact of a fiscal or monetary shock differs in a recession and an expansion phase. To integrate such a nonlinearity, the traditional class of VAR (or VECM) models are inadequate, as they are linear. Several alternative specifications have been proposed. Markov-Switching models (see Hamilton, 1989) provide with estimates of state dependent autoregressive coefficients and variance, as well as the transition matrix, which provides the probability of changing from one regime to another. The economic interpretation of the regimes is, however, uneasy as the latent variable governing the regime and the thresholds are not observed. To overcome this issue, studies generally compare the regimes obtained to acknowledged dating (i.e. NBER dating for business cycles), delivering hence an ex-post economic interpretation. As an alternative, Diebold et al. (1999) propose to let the transition probabilities vary with exogenous variables in order to determine the factors, which have an effect on the determination of the regime. Nevertheless, the threshold as well as an exhaustive list of the variables remains difficult to obtain.

We thus opt for another type of models. The multivariate Threshold VAR (TVAR) model (see Tsay, 1998) allows for a straightforward economic interpretation as they explicitly impose the threshold variable(s) and provide an estimate of the threshold(s) classifying the different regimes. In order to additionally take into account potential (co-)integration relations among the variables in the system, 
so-called threshold vector error correction models (TVECM) are widely used. In this class of models it is assumed that nonlinearities are determined by different long-run equilibrium dynamics, so-called "threshold co-integration" (e.g. Gonzalo and Pitarikis, 2007). However, potential nonlinearities within the short-run dynamics are not entirely covered by threshold co-integrated models. Moreover, counterpart theoretical models, as DSGE, always analyze shocks considering variables in deviation with respect to a fixed steady state. Hence, the model we propose can be seen as a (two regime) short-run threshold VECM given by

$$
\Delta y_{t}=\Pi y_{t-1}+\sum_{i=1}^{p-1} \Gamma_{i}^{A} \Delta y_{t-1} I\left(z_{t-d} \leq v\right)+\sum_{i=1}^{p-1} \Gamma_{i}^{B} \Delta y_{t-1} I\left(z_{t-d}>v\right)+u_{t},
$$

where $\Pi$ captures the common long-run equilibrium dynamics and $\Gamma_{i}^{A, B}$ the regime-specific short-run dynamics. As usual, $p$ is the lag order, and $u_{t}$ is the error term assumed to be a zero mean iid sequence of random vectors with covariance $\Sigma_{u}>0$. The determination of the regime to which $\Delta y$ belongs to at time $t$, depends on a threshold variable $z$ with delayed impact $d$ being less equal and greater, respectively, than the threshold $v$. It should be noted that shocks $u_{t}$ might differ across regimes, such that we can decompose the reduced-form residuals as $u_{t}=u_{t} I\left(z_{t-d} \leq v\right)+u_{t} I\left(z_{t-d}>v\right)$. Consequently, this will lead to regime dependent variance-covariance matrices $\Sigma_{u}^{A}$ and $\Sigma_{u}^{B}$. In the empirical part, this property will be crucial for the analysis of fiscal policies, which are identified from the regime depended variancecovariance matrices. These shocks will not modify the probability of exiting a particular state, but conditionally to the existing regime, it would be possible to evaluate the most efficient fiscal stimulus to 
stimulate economic activity.

We use the ML-principle to estimate the above model and adopt a Wald-type test, in order to test for regime presence. The estimation and testing procedure is elaborated in Candelon and Lieb (2010).

\section{$2.2 \quad$ Identification of the shocks}

In order to present the identification strategy, we will consider a standard linear $K$-dimensional VAR

model of the form

$$
y_{t}=A_{1} y_{t-1}+\ldots+A_{p} y_{t-p}+u_{t}
$$

where the innovations are assumed to be white noise as above. Note that this specification of the model is without loss of generality, since the results derived below hold equivalently for a threshold model as considered in the text.

What we are interested in, are the impulse responses that represent the effects of a (unit) shock in the variables of the system. Similar to the stationary case they are based on the MA representation of the process in (11) given by

$$
\begin{gathered}
\qquad y_{t}=\sum_{j=0}^{\infty} \phi_{j} u_{t-j}, \\
\text { where } \quad \phi_{n}=\sum_{j=1}^{n} \phi_{n-j} A_{j}, \quad n=1,2, \ldots
\end{gathered}
$$

with $\phi_{0}=I_{K}$ and $A_{j}=0$ if $j>p$. The forecast-error response of all variables in the system to a unit shock in the $k$-th variable $n$ periods ago are then given by $\phi_{n} \epsilon_{0}$ for any period $n=0,1,2, \ldots$, where $\epsilon_{0}$ is 
a $K \times 1$ initial shock vector with unity as $k$-th element and zero elsewhere.

We now face the problem of translating the forecast-error $u_{t}$ into economically interpretably shocks $\epsilon_{t}$. A commonly used approach is to orthogonalize the impulses using a decomposition $\mathcal{Q}$ of $\hat{\Sigma}_{u}$, that is, $\mathcal{Q} \mathcal{Q}^{\prime}=\hat{\Sigma}_{u}$. The orthogonalized responses are then given by $\Phi_{n}=\phi_{n} \mathcal{Q}$. Now, the impulses can be interpreted as transformed (structural) residuals of the form $\epsilon_{t}=\mathcal{Q}^{-1} u_{t}$, which are mutually orthogonal with unit variance, i.e. $E\left[\epsilon_{t} \epsilon_{t}^{\prime}\right]=I_{K}$. For further references let's denote $\mathcal{Q}$ as the impulse matrix, and let's define the point-estimates for the response of each variable of the system for a given impulse matrix, $n$ periods after the shock, as $\varphi_{n} \equiv \phi_{n} \mathcal{Q} \epsilon_{0}$, where $\varphi_{n}$ is a $K \times 1$ vector.

The one-to-one mapping from the vector of orthogonal (structural) shocks $\epsilon_{t}$ to the reduced-form residuals $u_{t}$ defined by a certain impulse matrix $\mathcal{Q}$ (e.g. a lower triangular Cholesky factor of $\hat{\Sigma}_{u}$ ) is, however, not unique. In order to uniquely identify all $K$ structural shocks in the system, i.e. uniquely identify the covariance structure, the researcher is faced the problem to impose $K(K-1) / 2$ restrictions on $\mathcal{Q}{ }^{6}$ Naturally, any kind of restrictions remain - to some degree - arbitrary or at least debatable.

Instead of uniquely characterize the impulse matrix $\mathcal{Q}$, i.e. to fully identify the structural model, we identify the model only partially, by imposing weaker restrictions that result in a set of impact matrices, and, hence, in a set of responses.

Most recently the method of "sign-restrictions" has become a quite popular tool to partially identify structural VARs. Since it was introduced by Uhlig (2005) and Canova and di Nicoló (2002), it has become

\footnotetext{
${ }^{6}$ For example, in the case of a Cholesky factorization, this is achieved by "setting" all $K(K-1) / 2$ upper-diagonal elements equal to zero. An other popular way of uniquely identifying the impact matrix, is to impose long (and/or short) run structural relationships among the variables, as e.g. in Bernanke (1986), Blanchard and Quah (1989) or Galí (1992)
} 
an extensively used identification scheme for applied macroeconomists. This method is used here on the impulse responses (i.e. on $\varphi_{n}$ ) to identify a set of impulse matrices.

We will call impulse matrices as well as responses valid if they fulfill the imposed restrictions. More specifically, note that any impulse matrix $\mathcal{Q}$ can be written as the product of one identified decomposition of $\Sigma_{u}$ (e.g. a lower triangular Cholesky factor $P$ ) and any orthogonal $K \times K$ matrix $Q$, i.e. $\mathcal{Q}=P Q$, is again a valid decomposition of $\hat{\Sigma}_{u} \forall Q \in O(K, \mathbb{R})$, where $O(K, \mathbb{R})$ denotes the orthogonal group over the reals. Basically, the idea about sign restrictions is now, to define a function over the set of all potential responses (i.e. associated with any $Q \in O(K, \mathbb{R})$ ) that keeps only those which are valid in the above sense.

In order to illustrate the (pure) sign restriction approach, let us assume in a first step that we would know the model's coefficients with certainty, i.e. we assume for the moment that $\phi_{n}, n=1,2, \ldots$ are deterministic (and equal for instance their LS-estimators). Now, we identify the model, by restricting some of the point-estimates for the response of each variable of the system for a given impulse matrix, for $n$ periods after the shock to follow the imposed signs. More formally, given an initial decomposition $P$, say a Cholesky decomposition of $\Sigma_{u}^{7}$, we compute for each "draw" of $Q$ the vector of point estimates of the responses to a unit shock in the $i-t h$ variable $\epsilon_{0}^{i}$ as $\hat{\varphi}_{n} \equiv \phi_{n} P Q \epsilon_{0}^{i}=\phi_{n} \mathcal{Q} \epsilon_{0}^{i}$ and sort out those that do not fulfill our imposed restrictions. Note that the above statement can be read equivalently as considering the "Cholesky-identified model" $\phi_{n} P$ which is not hit by a unit-shock only, but by infinitely

\footnotetext{
${ }^{7}$ In fact we do not use a Cholesky factorization as an initial decomposition of $\Sigma_{u}$ but a spectral decomposition. Moreover, we find that the identified set of impulse responses is robust with respect to the chosen initial decomposition.
} 
many shocks $\bar{\epsilon}_{0}=Q \epsilon_{0}^{i}$ which are distributed with equal probability on the $K-1$ unit-sphere $S^{K-1} .8$

It is straightforward to show that the set of "valid" structural shocks $\bar{\epsilon}_{0}$ is either empty or a compact

half-space of $S^{K-1}$.

The matrix $Q$ as well as the vector $\bar{\epsilon}_{0}$ are probabilistic by nature since it can be any matrix in $Q \in O(K, \mathbb{R})$ or any vector on $S^{K-1}$, but since they do not depend on the outcome of a random experiment, but are rather random measurements of a manifold elements, we will call them random primitives. We will consider any realization of $Q$ (and $\bar{\epsilon}_{0}$ ) as equally likely. To "draw" a matrix $Q$ we use the algorithm proposed by Stewart (1980), which generates samples from an uniform distribution (with respect to the Haar measure) from the orthogonal group. This approach based on Householdertransformation is numerically stable and computationally very efficient.

In the above example it is important to stress that the range of identified models does only represent a distribution across models and does not allow to make any profound probabilistic statement. ${ }^{9}$ Here we are, however, also interested in reflecting inference.

While the asymptotic as well as small-sample properties of the reduced-form parameters are well understood (e.g. Lütkepohl and Reimers, 1992 or Benkwitz et al., 2001), research to construct inference for partially identified structural VARs is still limited. ${ }^{10}$ Just recently, Moon et al. (2009) proposed how to construct inference in VARs identified with sign restrictions. We will here proceed similarly by

\footnotetext{
${ }^{8}$ It can be shown that the distribution is uniform with respect to the Haar measure.

${ }^{9}$ see: Fry and Pagan, 2010 for a critical review on the use of confidence bounds in partially identified models via sign restrictions

${ }^{10}$ The derivation of the asymptotic inference for the set of identified structural parameters is not straightforward since it involves the additive combinations of multivariate random variables defined on two different spaces with different metrics: the Euclidean and the Riemannian.
} 
considering the union of identified sets.

In the following we will consider IRFs up to horizon $h$. Moreover, it is assumed that the joint distribution of the reduced-form responses up to horizon $h, \phi^{h} \equiv\left[\phi_{0}, \ldots, \phi_{h}\right]$, is known and assumed to be tight. The support is assumed to be compact and given by $\mathcal{P} .^{11}$ Similar to the case of deterministic coefficients we will consider an impulse matrix $\mathcal{Q}$ as "valid" if $\phi^{h} \mathcal{Q}$ fulfills the imposed restrictions for all $\phi^{h} \in \mathcal{P}$. That is, for any "valid" impulse matrix $\mathcal{Q}$, we know that any response associated with that $\mathcal{Q}$ is in $\mathcal{S}(\mathcal{Q}) \equiv \bigcup_{\phi^{h} \in \mathcal{P}} \phi^{h} \mathcal{Q}$ with probability one. We call $\mathcal{S}(\mathcal{Q})$ an identified set. As above an impulse matrix $\mathcal{Q}$ is defined as the product of an initial decomposition $P$ and any orthogonal matrix $Q$. Again, it is straightforward to verify, that the set of "valid" $Q^{\prime}$ s is either empty or consists of a compact subgroup of $O(K, \mathbb{R})$, say $\mathcal{O}$. Consequently, any response satisfying the imposed restrictions must be in $\mathcal{S}^{*} \equiv \bigcup_{Q \in \mathcal{O}} \mathcal{S}(\mathcal{Q}(Q))$ with probability one.

Thus, in order to approximate a $100 \%$ confidence interval of the identified set of responses, we have to approximate $\mathcal{S}^{*}$. Instead of doing it analytically, we rely on the "trial-and-error" approach mentioned above.

\footnotetext{
${ }^{11}$ The support might be approximated by adequate re-sampling techniques for small sample refinements - this naturally results in a compact support. We apply the method proposed by Benkwitz et al. (2001) for bootstrapping VECM. If one would rely on asymptotic results for the distribution of $\phi^{h}$, the compactness assumption is not fulfilled necessarily. In such a case one could consider a truncated version of the distribution.
} 


\section{Empirical analysis}

\subsection{The data}

The data is the one used in Mountford and Uhlig (2009). It means that the model is composed by

10 variables: GDP, total government expenditure, total government revenue, interest rate, adjusted reserves, the producer price index for crude materials, the GDP deflator, private consumption, private non-residential investment, and real wages. The data has a quarterly frequency, cover the period 1960(I)$2000(I V)^{12}$ and is taken in logarithms (except of interest rates).

\subsection{Identification of the regimes}

The first step of the empirical analysis consists in estimating for a threshold and in testing for the presence

of regimes, using the estimating and testing strategy proposed in Candelon and Lieb (2010). ${ }^{13}$ We also have to predetermine the minimum number of observations in a single regime. A trimming value of $20 \%$

(i.e. 33 observations) is imposed. ${ }^{14}$ In order to specify the model, we extend standard model selection criteria to determine the model's lag-order and the delayed influence of a given threshold variable. We

first consider four potential variables that may govern regimes: GDP, consumption, investment and the

Dow Jones stock market index, all expressed in growth rates. The results of the tests, which are reported

in Table 1, indicate that regimes are not driven by stock market indices, but rather by real activity

\footnotetext{
${ }^{12}$ Such a sample has been chosen to allow for the comparison with the ones obtained by Mountford and Uhlig (2009).

${ }^{13}$ Since the threshold is not identified under the null, we are facing the so-called nuisance parameter problem. Following Davies (1987) and Hansen (1996), and Andrews and Ploberger (1994), we propose to use the supremumn (supW) or exponentially weighted averages $(\exp W)$ of the initial test statistic instead. The asymptotic distribution of $\sup W$ and/or $\exp W$, which depends on the moments of the process, is approximated in Candelon and Lieb (2010).

${ }^{14}$ This choice slightly departs somehow from Davies (1987) who suggests a value of $15 \%$. Nevertheless, allowing a regime to cover less than 30 observations would render the estimate a 10-variate VAR with 2 lags quite heroic, as it would be subject to severe bias. Besides, statistical inference on the parameters will be unprecise as the degree of freedom of the tests would extremely small.
} 
indicators such as GDP, consumption and investment. This constitutes already a strong conclusion as policy shocks identified in the next subsection would not depend on stock market indices fluctuations but instead to real economic conditions. To assess this point and to have an aggregate variable, we consider the Stock and Watson coincident indicator $(X C I)$, which is non observed and can be considered as weakly exogenous but constructed as a linear combination of fundamental macroeconomic variables. ${ }^{15}$

The threshold test indicates that XCI constitutes indeed an adequate variable underlying regimes. The decision to consider the $X C I$ as the optimal threshold variable is, however, not only based on the above reasoning and gut feeling, but can also be justified from an econometric perspective, as it is the threshold variable that leads to the smallest forecast MSE - no matter what model selection criteria is considered.

\section{[Table 1 about here]}

In Figures 1 we report the states obtained using the different variables. It is noticeable the ones associated with the $X C I$ are similar to the ones obtained by using GDP or consumption and to a lesser extent to those obtained by using investment as a threshold variable. Moreover, comparing the regimes associated with the $X C I$ and the official NBER recession dates, it is straightforward to conclude that regimes can be interpreted as downward and upward phases of the business cycles. As for business cycle expansion and recession, it can be observed that upward regimes are longer and milder than downward states (see Neftci, 1984 and Hamilton, 1989). This preliminary analysis conveys the idea that policy shocks differ if the economy is in an expansion or a recession. It is therefore important to analyze the

\footnotetext{
${ }^{15}$ An alternative would consist in considering that regimes would depend a multiple variables. Nevertheless, this way will be much more time demanding and could be biased by the high correlation between fluctuations in GDP, consumption and investment.
} 
(different) pattern of fiscal policy shocks across regimes in order to obtain optimal efficiency. To this aim

the next step consists in identifying them.

\subsection{Policy shocks identification}

As the estimation of the TVECM leaves us with shocks, which are not economically interpretable, the aim of the identification consists in finding linear combinations of shocks, which can be interpreted as policy (monetary or fiscal) impulses. We pay our attention to two particular points.

First, while there is a broad (theoretical) agreement on how to describe a monetary policy shock, (i.e. a sudden change in the interest rate), there is no consensus to characterize fiscal policy shocks. Following Mountford and Uhlig (2009), fiscal policy will be decomposed into government expenditure and government revenue shocks. A combination of these two scenarios will then be interpreted as a fiscal policy shock (e.g. deficit financed tax-cut or deficit spending).

Second, as we aim at identifying the active or discretionary policy shocks, cyclical effects have to be controlled for. Without this precaution, one would not obtained policy shocks but rather a combination of discretionary impulse and automatic stabilizers. As an example, during a recession government revenue and deficit automatically shrinks without indicating a restrictive fiscal policy. Thus, to avoid this problem, restrictions are set up to impose the orthogonality of all ${ }^{16}$ policy impulses to business cycles shocks.

Our approach incorporates the two previous remarks. Three basic policy impulses are identified (a government revenue, a government expenditure, and a monetary policy shock) as well as a business cycle

\footnotetext{
${ }^{16}$ This constitutes a slight difference with Mountford and Uhlig (2009) which only impose such a restriction for expansionary monetary policy.
} 
shock. The identification is performed via a pure sign-restriction approach. In contrast to Mountford and

Uhlig (2009) we do not use a penalty function, but impose the direction of an impulse responses function after a policy shock for 4 quarters. ${ }^{17}$

The business cycle shock is assumed to move government revenue, output, consumption, and investment in the same direction for four quarters after the shock. Note, that a business cycle shock can be either positive or negative. This is a minimum characterization of a business cycle shock, and mainly driven by the idea that if government revenue and output move in the same direction this can only be due to a business cycle improvement or deterioration. The positive (resp. negative) monetary policy shock moves prices and foreign reserves down (resp. up), and interest rates up (down) during the first year after the shock. Finally, a basic government expenditure (resp. a basic government revenue) shock is identified by an increase in government purchases (resp. government revenue) for the first four quarters after the shock. Table (2) summarizes the imposed sign restrictions on the IRFs.

\section{[Table 2 about here]}

Practically, it means that we will only retain IRF satisfying the previous sign scheme. Nevertheless, to tackle remark 2, i.e. to ensure the orthogonality between the business cycle and the policy shocks, identification has to be performed sequentially. In a first step, the business cycle shocks are identified in line with the sign reported in Table 2 . Then, monetary shocks are identified by signs and by orthogonality to the business cycle shocks. Finally, the identified fiscal policy shock (government revenue and expendi-

\footnotetext{
${ }^{17}$ See, for instance, Caldara and Kamps (2008) for discussion and critical review of the different identification approaches in the context of assessing fiscal policy with sign restrictions.
} 
ture) satisfies the restrictions set-up in Table 2 and is orthogonal to the two other shocks (business cycles and monetary shock).

\section{Results}

In order to make the results of our identification scheme comparable to the existing literature, we present the IRFs of the linear VECM for the basic shocks in Figures 2-3. The results are qualitatively similar to those reported in Mountford in Uhlig (2009). The slight differences can be traced back to the fact that 1.) we consider the co-integration relations in our model and 2.) we use a pure sign-restriction approach to identify the shocks.

Before interpreting the regime-specific results, we would like to recall, as already mentioned in section 2 , that our model does not allow for economic policies to have impact on the regime determination. Thus, the efficiency of a policy is not evaluated by its ability to increase the probability of exiting a bad state or staying in a good regime. Instead, conditionally to the prevailing regime (determined in a first step) we aim at investigating which policy would have the largest stimulating impact on GDP and via which channels. Because we do not model the transmission process between the regimes, the IRFs reported below are only informative in the short-run. We consider a time period of 7 quarters corresponding to the average duration of a recession as identified above. 


\subsection{Basic government spending shock}

The IRFs of the basic government spending shock are plotted in Figure 4. On the first sight, the economy seems more reactive to government purchases in expansions than in recession. But this can be traced back on the one hand to the fact that government expenditures are much higher than in recession; and this constantly over the whole period considered. It is also noticeable that the response of the economy is more volatile in recession than in expansion, because of the fluctuating response of government revenue.

While we can interpret the basic expenditure shock in good times rather as deficit spending shock (since government revenue does not change significantly) things look different for regime-specific dynamics in crisis. Here, the basic spending shock does not lead to clear-cut interpretation and hence should be considered with caution.

In recession we find a stimulating effect of increasing government purchases on consumption. This positive effect is recently supported in related papers as well and is theoretically founded in some NewKeynesian models (e.g. Gali et al., 2007). Moreover, we find short-lived crowding-out effects of investment, despite decreasing interest rates.

In expansionary periods the impact on key variables as consumption and investment is rather insignificant. Especially, we do not detect evidence for crowding-out effects of investment. Here, the significant increase in output can, thus, mainly traced back to the spending policy itself. Interestingly, we find a positive reaction of real wages, which is in accordance with New-Keynesian theory. 


\subsection{Basic government revenue shock}

The IRFs for the basic revenue shock are displayed in Figure 5. The economy seems now to exhibit a stronger reaction in recession than in expansion. The regime-specific dynamics are rather intuitive, since GDP, real wages, and investment tend to fall. However, consumption is not affected significantly. The positive reaction of prices and interest rates are somewhat puzzling, but in line with the findings of Mountford and Uhlig (2009). However, the results have to be read with caution again, since it is not clear whether the dynamics are stimulated via an increase in taxes, or a decrease in government spending, which declines significantly.

In expansion, the output does not seem to react to a sudden tax increase. Since the increase in government revenue is significantly lower than in recession and the reaction of government spending is questionable, a direct comparison of regime-specific dynamics is - again - not straightforward. However, neglecting the magnitude of the responses, the results are rather similar to those in recession. One striking difference certainly lies in the response of investment. In expansion, investment (while initially reduced) seems to be crowded-in after the first periods by a tax-increase, while the opposite holds in recession. Again, whether this is due to different reaction of government purchases is not clear.

\subsection{Some fiscal policy scenarios}

As we have seen above, the regime-dependent responses of government purchases and revenues to one of the basic shocks differ qualitatively and quantitatively across regimes. This makes a direct comparison of 
the regime-specific IRFs rather difficult, simply because the policy shock identified in one regime cannot

be considered to be the same as the one identified in the other.

Thus, it would be helpful to compare (quantitatively) identified policy shocks instead. For instance, one could think of a policy scenario, where government purchases rise exactly by $1 \%$ for a year, while government revenues remain unchanged for the same period. Although there is a huge number of such fiscal stimuli most of them can be assigned to one of the following classes: a deficit-spending policy or a deficit financed tax-cut policy, which will be examined both. ${ }^{18}$ In contrast, the monetary policy instrument is well summarized by interest rates variations.

As in Mountford in Uhlig (2009) we think of the above mentioned fiscal shocks as a linear combination of the basic expenditure and revenue shock. For example, a deficit spending scenario is defined as a linear combination of the basic fiscal shocks, such that government spending increases by $1 \%$ for the first 4 quarters after the shock, while government revenue remains unchanged for the same time.

The effectiveness of a fiscal policy measure is often evaluated in terms of its multiplier effects. We will consider two types of multipliers to assess the above mentioned fiscal shocks: the impact multiplier (IM) and the present-value multiplier (PVM). We additionally impose a restriction on the linear combinations of basic shocks concerning the height of the multiplier (IM and PVM). Multiplier effects that exceed 3 or -1 during the first year after the shock, are considered to be unrealistic. ${ }^{19}$ Although this is certainly

\footnotetext{
${ }^{18}$ Unlike in some of the mentioned related papers, we will not consider balanced-budget policies in the following, since the assessment of the effectiveness of deficit driven policies is our key concern.

${ }^{19}$ More formally, the deficit-spending shock in each regime defined as a linear combination of the regime-dependent basic spending (BS) and basic revenue (BR) shocks requires that $0.01=\sum_{j=0}^{h}\left(r_{G S, B S}(h-j) B S_{j}+r_{G S, B R}(h-j) B R_{j}\right)$ and $0=\sum_{j=0}^{h}\left(r_{G R, B S}(h-j) B S_{j}+r_{G R, B R}(h-j) B R_{j}\right)$ for $h=0, \ldots, 4$, as well as $-1 \leq P V M_{h} \leq 3$ and $-1 \leq I M_{h} \leq 3$ for $h=0, \ldots, 4$, where $r_{G R, B S}(h)$ denotes the response at horizon $h$ of government revenue to the basic spending shock.
} 
a "more than reasonable" upper boundary, Mountford and Uhlig (2009) found multiplier effects - based on the median response - that exceed this value. We are convinced that such a restriction provides a deeper insight into the size of a reasonable multiplier. Besides, imposing such "economically founded" boundaries is also suggested by Kilian and Murphy (2010) in their analysis of the effect of oil price shocks.

\subsubsection{A deficit financed spending policy scenario}

The IRFs consecutive to a deficit financed spending shock are reported in Figure 6. Let us first consider the economy's dynamics in the phase of expansion: output, consumption, and real wages are clearly affected positively, while investment is not affected significantly. As for the basic expenditure shock, we do not find any other variable to change significantly after a deficit-financed spending scenario in booming phases.

Considering recession periods we find - as for the basic spending shock - that consumption is stimulated much stronger in recession. This does not lead, however, to a significantly higher increase in output, since investment is almost completely crowded-out in bad periods. Another interesting insight is, that prices react insignificantly in recession but tend to decrease in expansion.

To summarize, we do not find "Non-Keynesian" effects of fiscal policy in recession (as in Perotti, 1999) but rather strong Keynesian effects mainly because of a strong impact on consumption.

\subsubsection{Deficit financed tax-cut policy scenario}

Figure 7 reports the IRFs consecutive to a deficit financed tax-cut shock, which is a sequence of basic fiscal shocks, designed such that government revenue decreases by $1 \%$ for the first 4 periods after the 
shock, while government expenditures are remaining unchanged for the same time. Compared with the deficit spending scenario, one observes right away that for almost all variables the reaction is slightly weaker - no matter what economic condition we are looking at. This result is clearly in opposition to the findings of Blanchard and Perotti (2002) and Mountford and Uhlig (2009) who conclude that a tax-cut to be more effective than direct spending policies. The increase in GDP is here driven by a boost in investment while consumption reacts rather insignificantly. Interestingly, the increase in investment is only strong in times of recession and we do not find that a tax-cut stimulates investment in expansion. As a consequence the impact on output in periods of expansion is weaker and getting insignificant after a few periods. It is also worth mentioning that prices react negatively (and similar in both regimes) on the policy considered here; what again remains a well-known puzzle in this literature.

\subsubsection{Quantitative Assessment of Policy Scenarios}

In order to allow for a deeper comparison between different policy scenarios, it is helpful to consider measures that evaluate the effects quantitatively. In this context multipliers are often used in the literature. They assess the effect of a policy action in terms of GDP response. In Table 3, two different multipliers are reported for the median response: the impact multiplier (IM) and the present-value multiplier (PVM). The first one is probably the most often used measure (e.g. Blanchard and Perotti, 2002; Canova and Pappa, 2007; Mountford and Uhlig, 2009). It simply represents the ratio of the response of GDP at a given period to the initial movement of the fiscal variable. The present-value multiplier (as defined in Mountford and Uhlig, 2009) captures the discounted impact of a scenario along the entire path of the 
responses up to a given period. ${ }^{20}$

Interestingly, the spending-multiplier always exceeds unity - whatever the measure is and whether we are in recession or not. On the contrary, this does not hold for the tax-multiplier which can be lower than one. Especially, the initial impact of a deficit financed spending policy seems to be more drastic than a tax-cut.

\section{[Table 3 about here]}

To give a deeper probabilistic statement, Figure 8 reports the confidence bounds for the multipliers

for both policy measures considered. Looking at the first period after the policy measure took place,

it is noticeable that deficit spending stimulates the economy most significantly in recession. However, the difference across regimes seem to converge after a year. The opposite holds for the tax-cut scenario.

While the initial impact on the economy is quite low in recession (compared to boom periods), it seems to increase steadily. However, for the time span considered, the tax-cut multiplier never exceeds unity and rarely exceeds the effect of a spending policy significantly. It is thus straightforward to recommend spending policy action for government facing a recession phase. It has to be stressed, however, that these results must not be seen as a long-run policy advice, since we did not take any debt issue into account. ${ }^{21}$

\footnotetext{
${ }^{20}$ More formally, denote $y_{j}$ and $f_{j}$ the response of output and the response of the fiscal variable at period $j$, respectively. The impact multiplier at horizon $h$ is then defined as $I M_{h}=\frac{y_{h}}{f_{0}} \frac{1}{f / \bar{y}}$, where $\bar{f} / \bar{y}$ is the average share of the fiscal variable in GDP over the sample. If we denote $\bar{i}$ as the average interest rate over the sample, we can define the the present-value multiplier $h$ periods after the shock as $P V M_{h}=\frac{\sum_{j=0}^{h}(1+\bar{i})^{-j} y_{j}}{\sum_{j=0}^{h}(1+\bar{i})^{-j} f_{j}} \frac{1}{f / \bar{y}}$. Note that for calculating the tax-cut multiplier the response of the government revenue is negative, consequently $f_{j}$ has to be multiplied by $(-1)$ in this case.

${ }^{21}$ This cautious note takes its source in the empirical analysis, which is based on the same data considered in Mountford and Uhlig (2009), which does not include a debt variable. However, the integration of debt is likely to play an important role in that context, especially for European countries.
} 


\section{Concluding remarks}

This paper proposes to investigate the efficiency of fiscal policy shocks in the United States. To this aim, we use a Threshold Vector Autoregression framework as well as sign restrictions to identify structural policy shocks and evaluate the effect via impulse response functions in each regime. We aim at answering three questions: First, are fiscal policy shocks regime dependent? Second, which variables are governing the regime? Third, what are the effects of fiscal policies on the main macroeconomic variables in each of these states? It turns out that the hypothesis of linearity of the VECM parameters is strongly rejected, leading us to detect two regimes, identifiable clearly as recession and boom phases, respectively. Interestingly, the nonlinearity is not driven by stock market indices, but rather by the Stock and Watson coincident index proxying the business cycle stance.

Based on that piecewise model we are able to investigate regime depended dynamics using IRFs identified by a pure sign-restriction approach. We do not find "Non-Keynesian" effects of fiscal policy, neither in recession nor in expansion, but rather the contrary. A deficit-spending policy seems to be more efficient to stabilize the economy in the short-run than a tax-cut policy. This result holds in for both regimes. Nevertheless, the short-run multiplier effects exceeds unity significantly only in recession. Although the overall impact is smaller, the tax-cut policy seems to be more effective in times of economic slowdown.

While the spending policy boosts output via an increase in consumption, a tax-cut stimulates investment which then is the major driving force for a rising GDP. The impact on those key variables is stronger 
in times of recession. Interestingly, crowding-out effects of spending on consumption occur only in periods of stress. It has nevertheless to be emphasized that this policy advice should be taken with precaution and must not be considered as a carte blanche approval for politicians to run enormous budget deficits. Since the effectiveness of the considered policy measures is only assessed in the short-run, it naturally neglects any long-run consequence of increasing debts. 


\begin{tabular}{|c|c|c|c|c|c|}
\hline Threshold & $\begin{array}{c}\text { Lag-order } \\
\text { of the Model }\end{array}$ & $\begin{array}{c}\text { Lagged Impact of } \\
\text { the threshold Variable }\end{array}$ & $\begin{array}{l}\text { Threshold } \\
\text { estimator }\end{array}$ & $\begin{array}{l}\text { Obs. Lower/ } \\
\text { Upper Regime }\end{array}$ & p-value \\
\hline $\mathrm{XCI}$ & 2 & 2 & 1.5 & $\begin{array}{l}41 / \\
117\end{array}$ & $\begin{array}{l}P_{\text {sup }}=0.000 \\
P_{\text {exp }}=0.000\end{array}$ \\
\hline Dow Jones & 2 & 0 & -3.6 & $\begin{array}{l}38 / \\
120\end{array}$ & $\begin{array}{l}P_{\text {sup }}=0.147 \\
P_{\text {exp }}=0.141\end{array}$ \\
\hline GDP & 2 & 2 & 1.2 & $\begin{array}{l}33 / \\
125\end{array}$ & $\begin{array}{l}P_{\text {sup }}=0.000 \\
P_{\text {exp }}=0.000\end{array}$ \\
\hline Investment & 2 & 0 & -4.2 & $\begin{array}{l}34 / \\
124\end{array}$ & $\begin{array}{l}P_{\text {sup }}=0.000 \\
P_{\text {exp }}=0.000\end{array}$ \\
\hline Consumption & 2 & 0 & 1.2 & $\begin{array}{l}31 / \\
127\end{array}$ & $\begin{array}{l}P_{\text {sup }}=0.007 \\
P_{\text {exp }}=0.007\end{array}$ \\
\hline
\end{tabular}

Table 1: Regimes estimates 


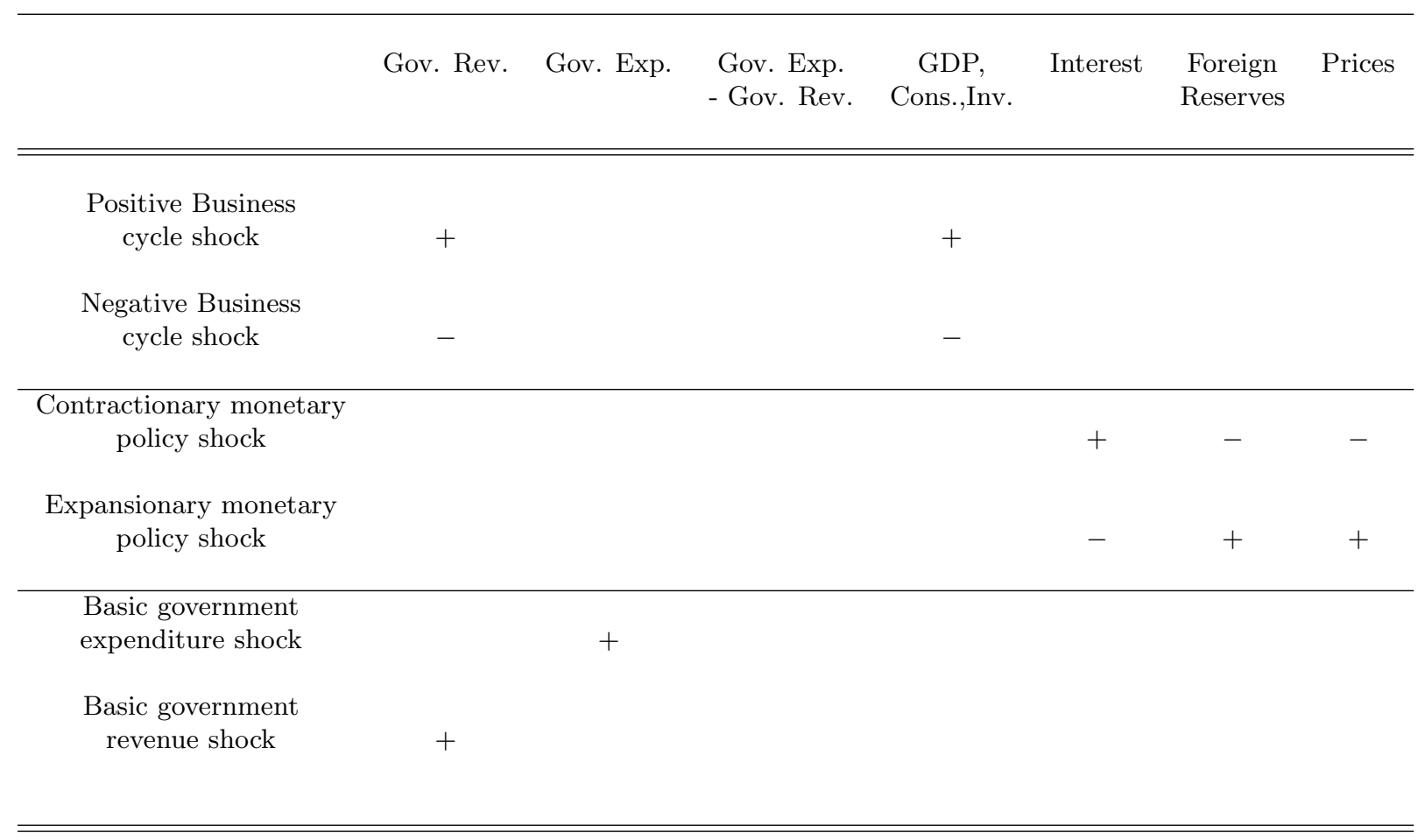

Table 2: Sign restrictions

Recession Boom

Def. Spending Tax-Cut Def. Spending Tax-cut

\begin{tabular}{l|cccc|cccc}
\hline & IM & PVM & IM & PVM & IM & PVM & IM & PVM \\
\hline 1 qrt & $\mathbf{1 . 8 8}$ & $\mathbf{1 . 8 8}$ & 0.28 & 0.28 & $\mathbf{1 . 0 8}$ & $\mathbf{1 . 0 8}$ & 0.84 & 0.84 \\
2 qrt & $\mathbf{1 . 2 5}$ & $\mathbf{1 . 5 8}$ & 0.49 & 0.38 & $\mathbf{1 . 2 9}$ & $\mathbf{1 . 1 8}$ & 0.86 & 0.85 \\
3 qrt & $\mathbf{1 . 0 1}$ & $\mathbf{1 . 4 0}$ & 0.97 & 0.56 & $\mathbf{1 . 6 4}$ & $\mathbf{1 . 3 2}$ & 0.75 & 0.82 \\
4 qrt & $\mathbf{1 . 3 9}$ & $\mathbf{1 . 3 9}$ & $\mathbf{1 . 1 1}$ & 0.69 & $\mathbf{1 . 5 2}$ & $\mathbf{1 . 3 7}$ & 0.56 & 0.76 \\
5 qrt & $\mathbf{1 . 1 8}$ & $\mathbf{1 . 4 0}$ & $\mathbf{1 . 3 0}$ & 0.79 & $\mathbf{1 . 5 0}$ & $\mathbf{1 . 3 9}$ & 0.65 & 0.74 \\
6 qrt & $\mathbf{1 . 2 1}$ & $\mathbf{1 . 4 1}$ & $\mathbf{1 . 3 8}$ & 0.85 & $\mathbf{1 . 4 6}$ & $\mathbf{1 . 4 1}$ & 0.78 & 0.75
\end{tabular}

Table 3: Impact multipliers (IM) and present-value multipliers (PVM) calculated for the median-response. Note: Multiplier effects that exceed unity are highlighted. 
Threshold variable: yearly growth rate of the $\mathrm{XCl}$

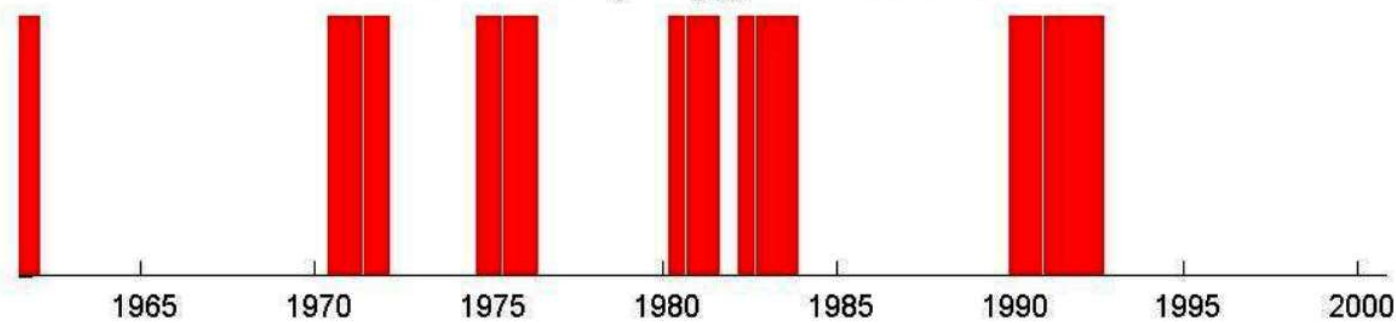

Threshold variable: yearly growth rate of the GDP

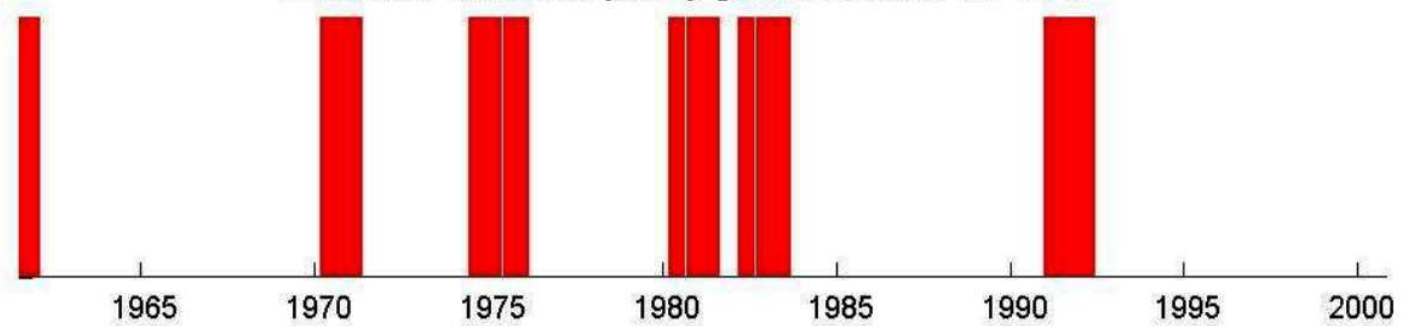

Threshold variable: yearly growth rate of investment

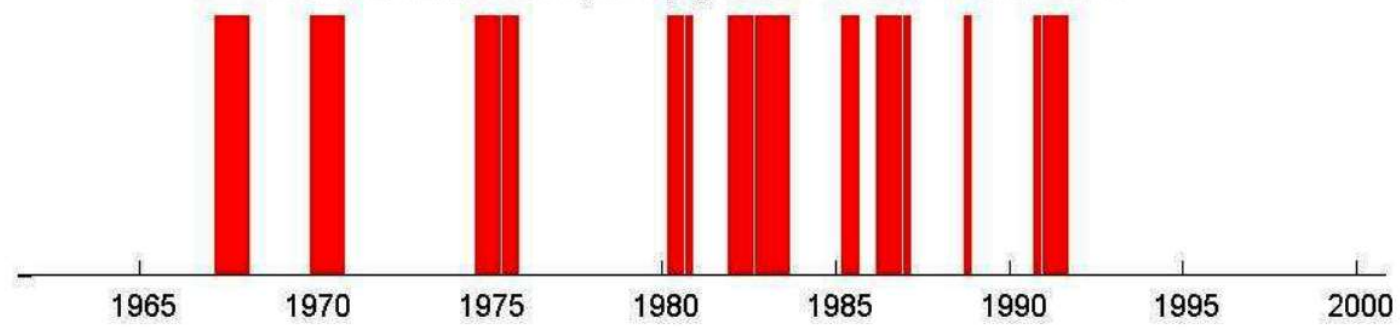

Threshold variable: yearly growth rate of consumption
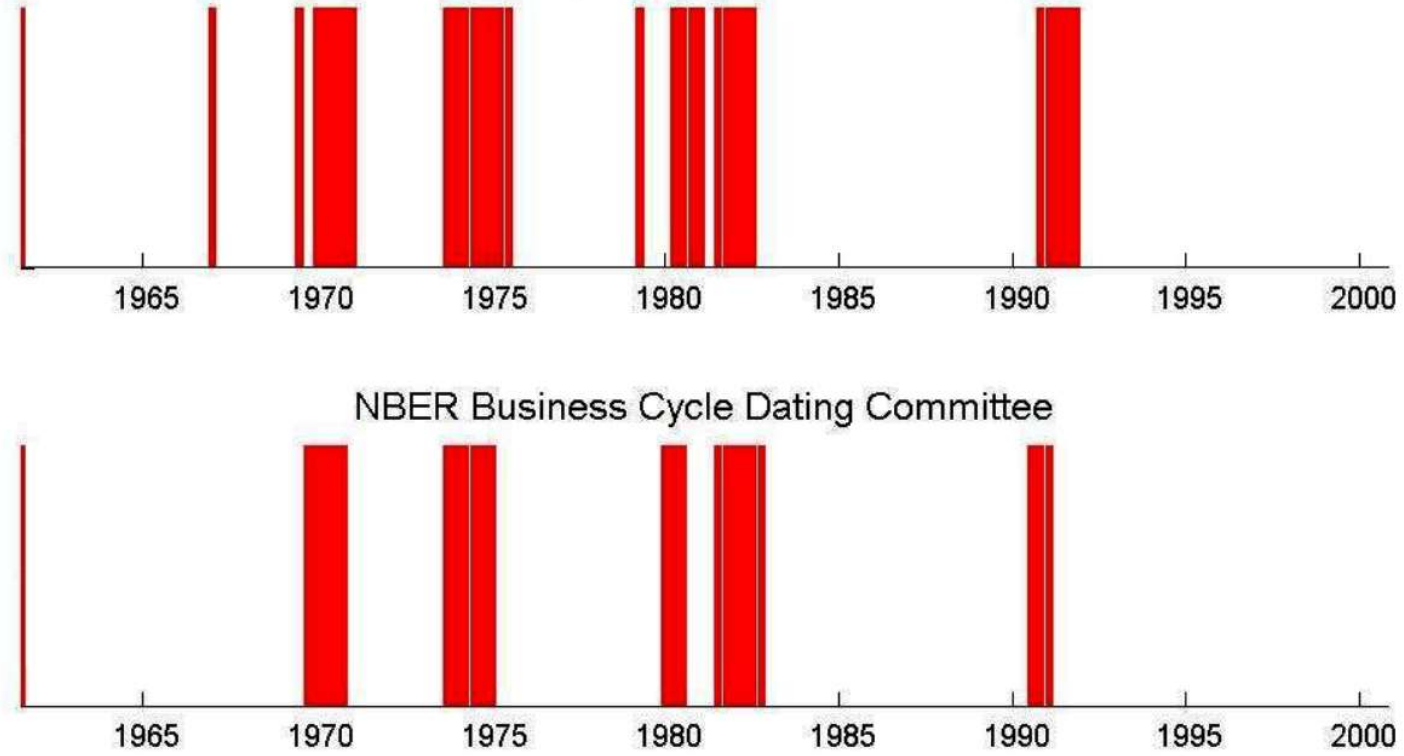

Figure 1: Periods of recession obtained the several threshold variables. Note: The NBER recession dates are plotted for sake of comparison. 
The basic government expenditure shock

GDP
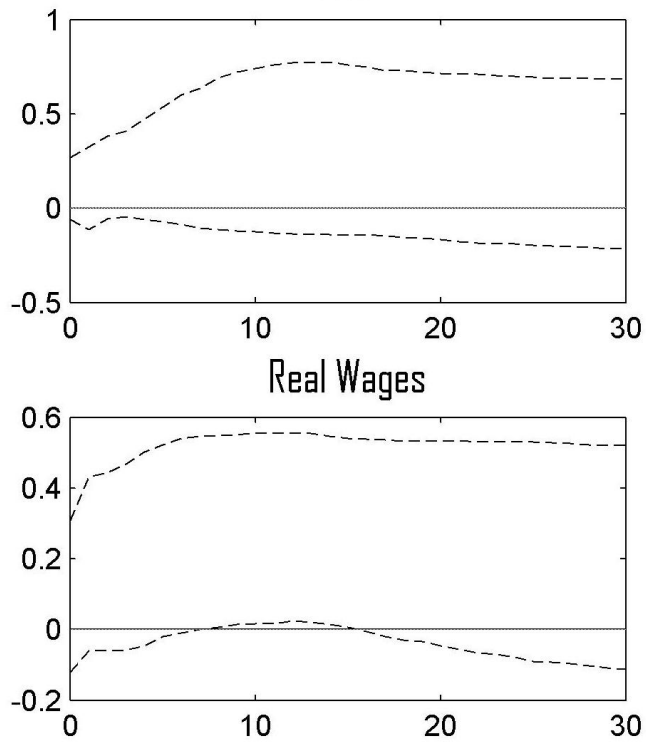

Gov. Spending
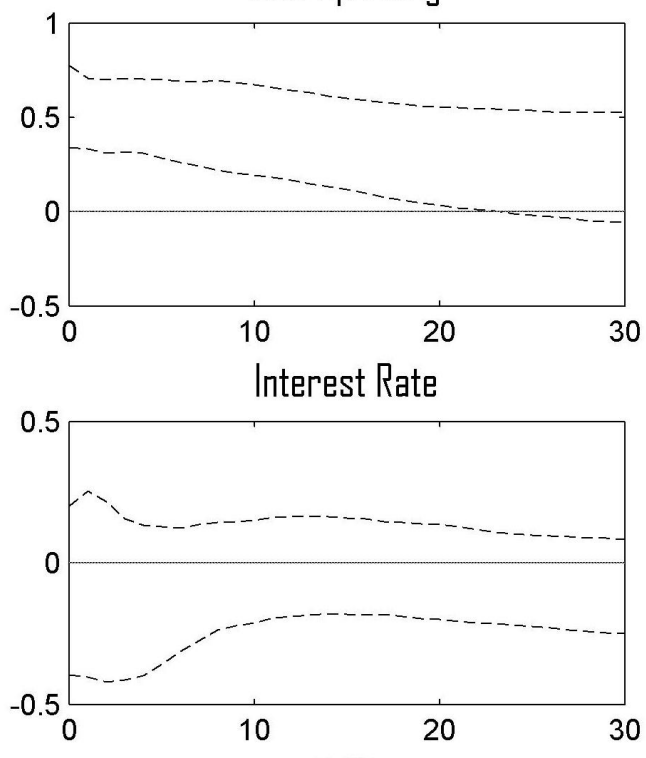

PPIC

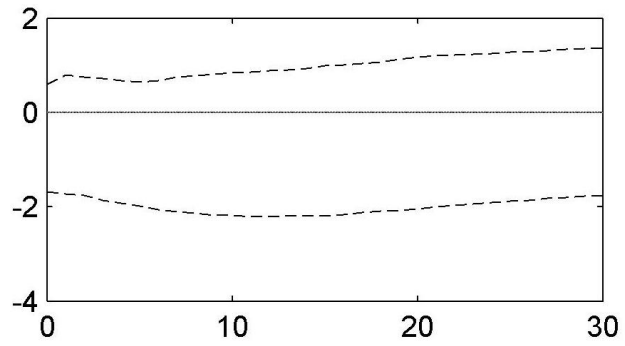

Consumption
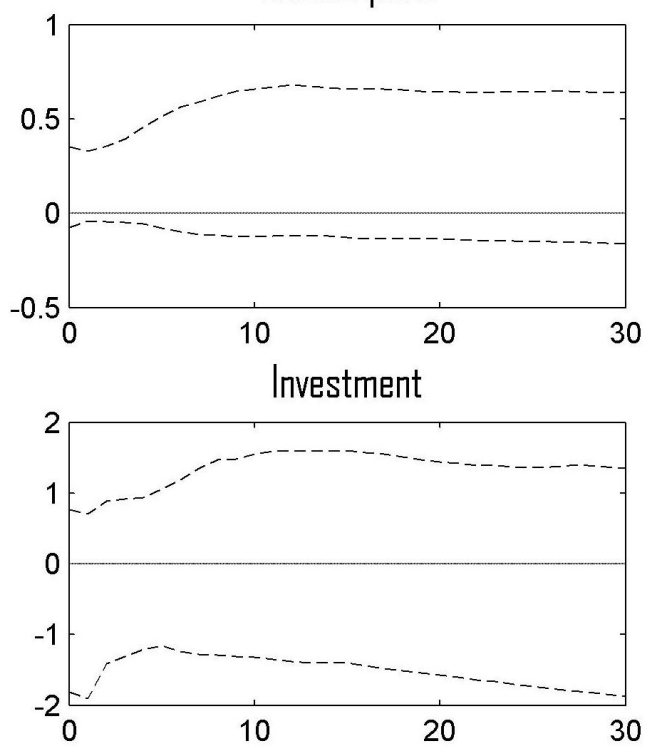

Gov. Revenue

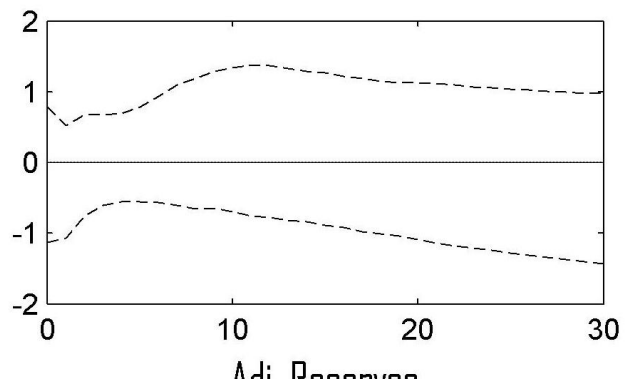

Adj. Reserves

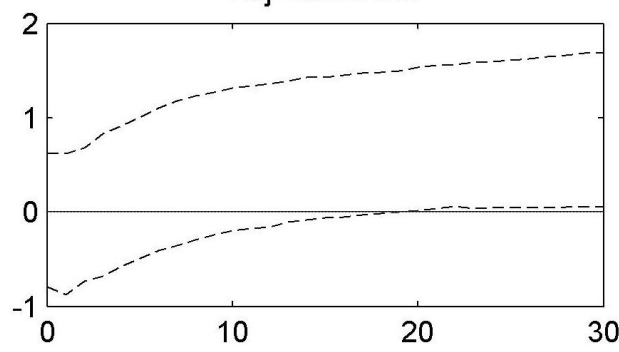

GDP Deflator

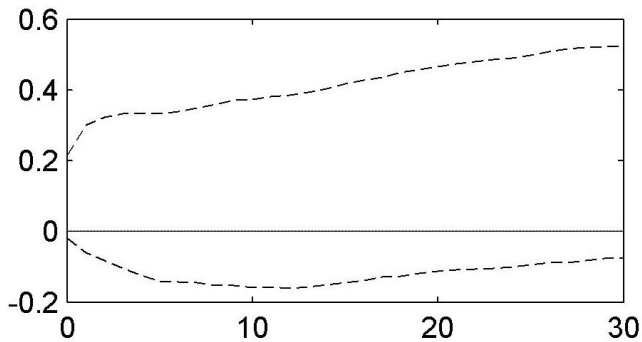

Figure 2: Confidence bounds of the linear model as a benchmark. 
The basic government revenue shock
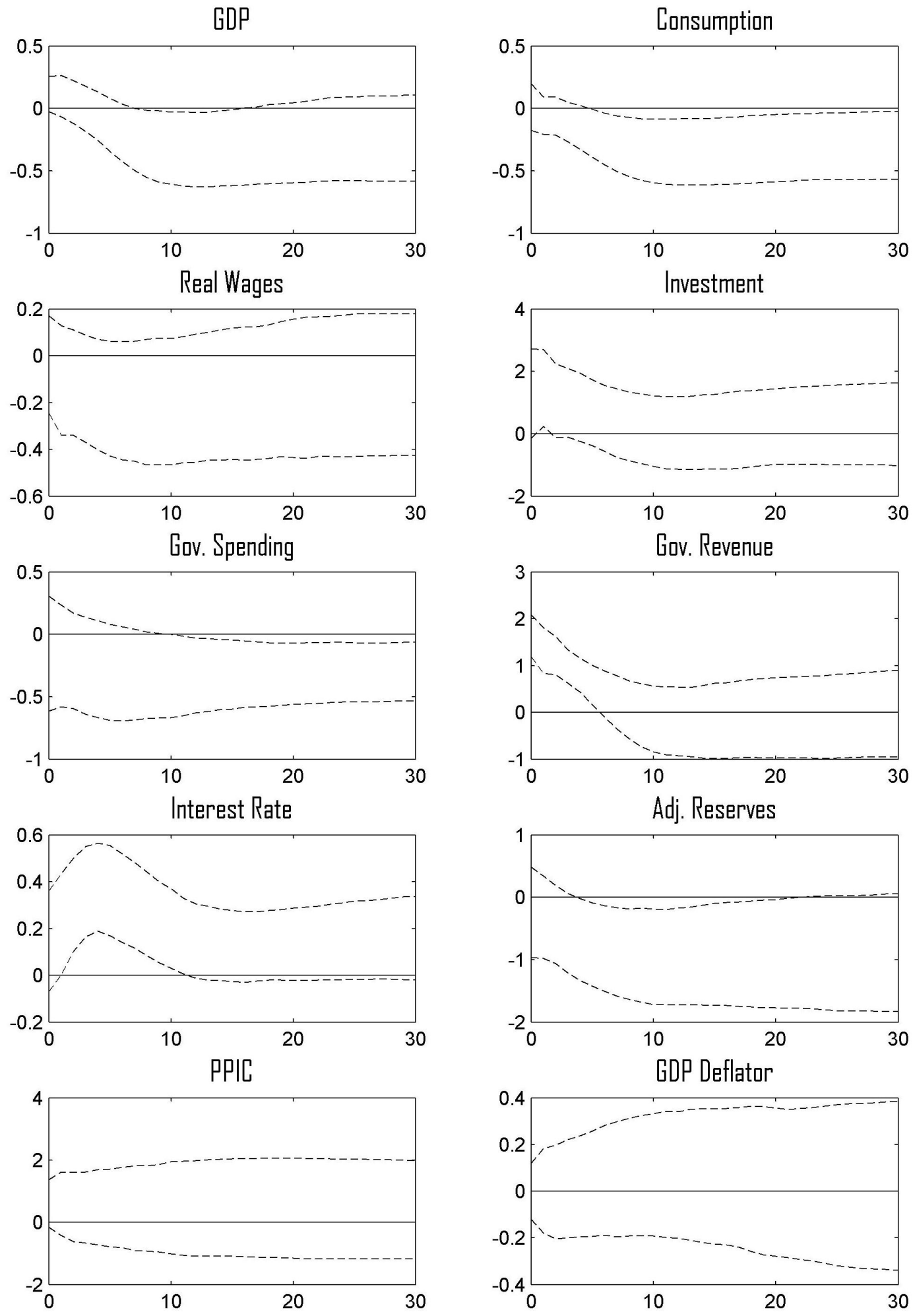

Figure 3: Confidence bounds of the linear model as a benchmark. 
The basic government expenditure shock
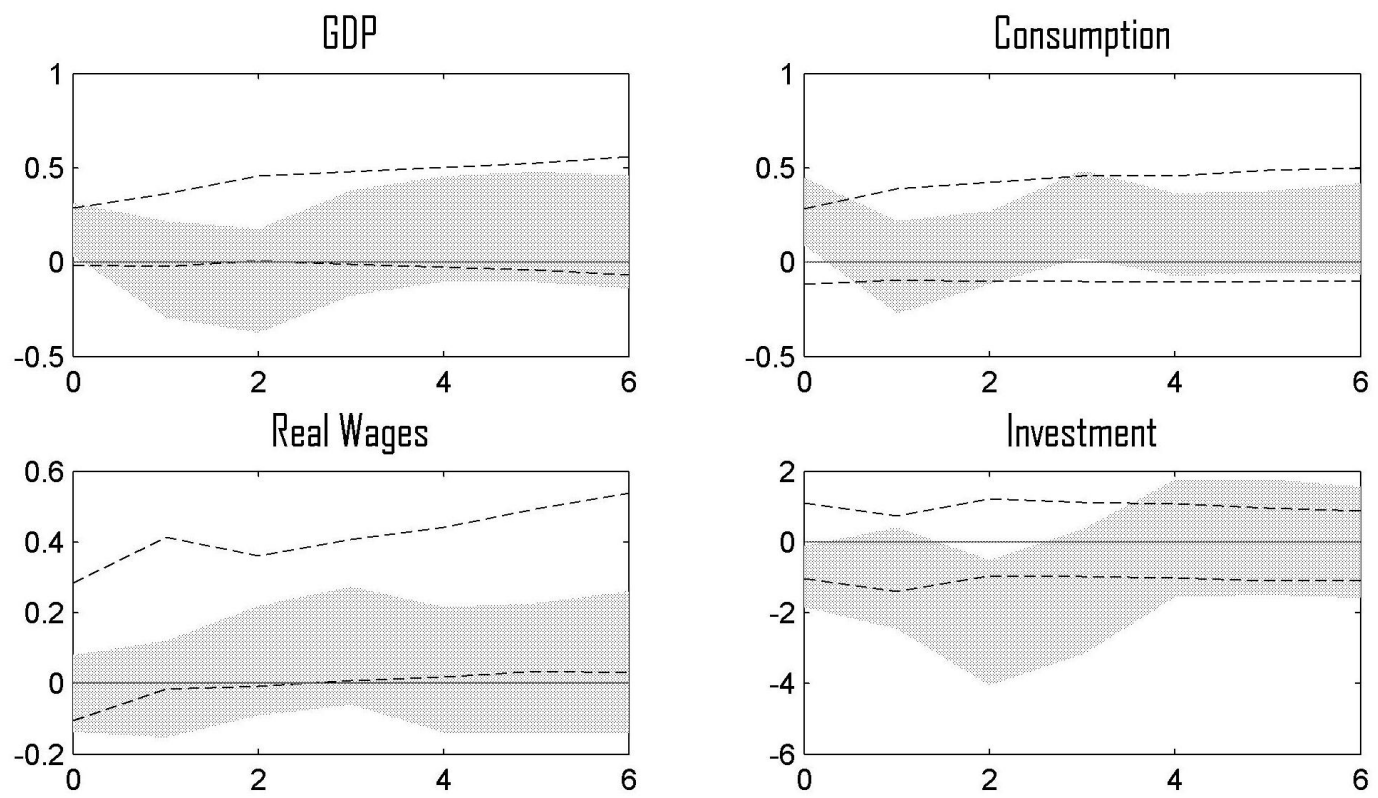

Gov. Spending
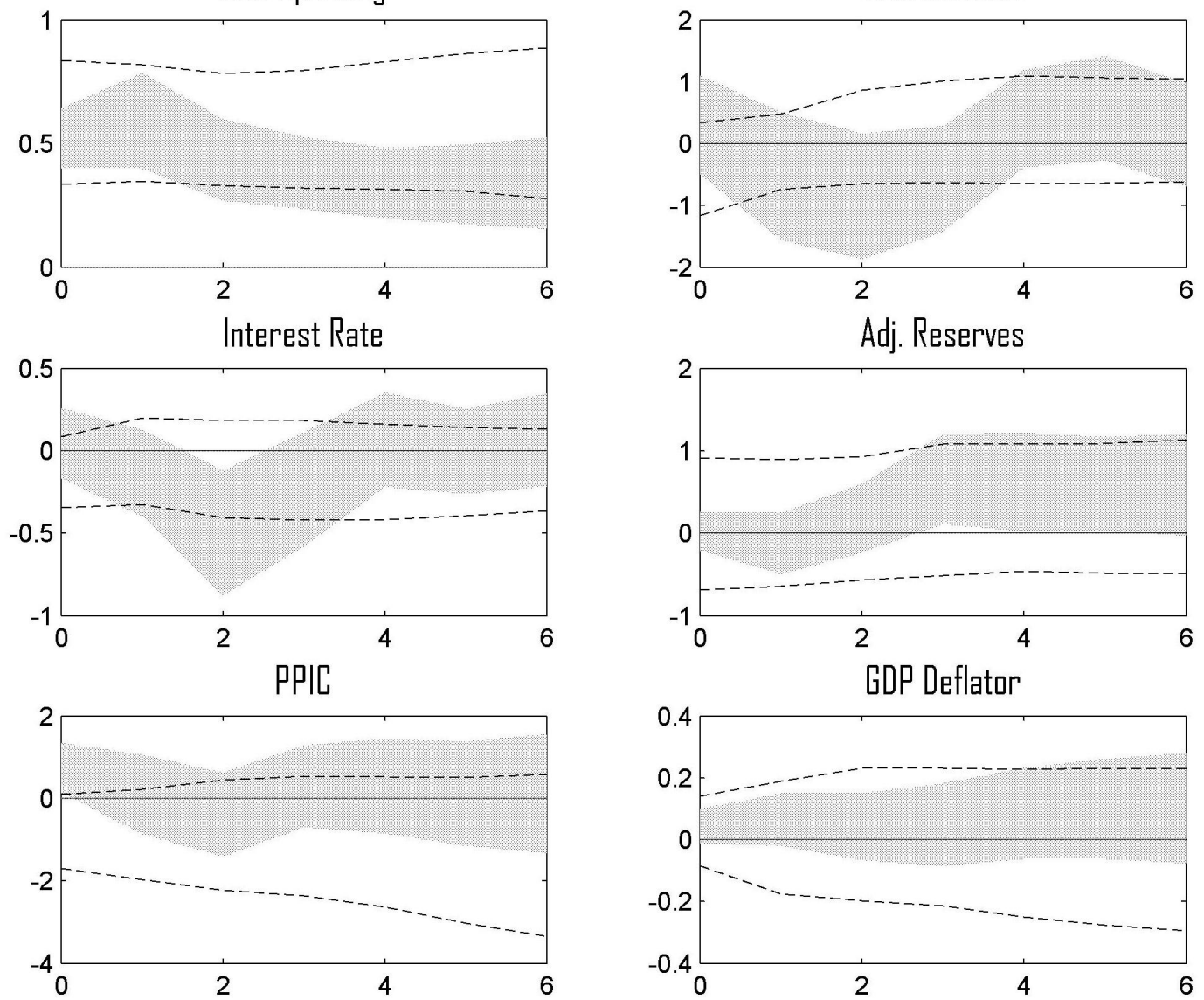

Figure 4: Confidence bounds of the identified sets of the basic government spending shock. The shaded area indicates the $68 \%$-confidence set in recession, the dashed lines indicate the confidence set in 'normal times'. 
The basic government revenue shock
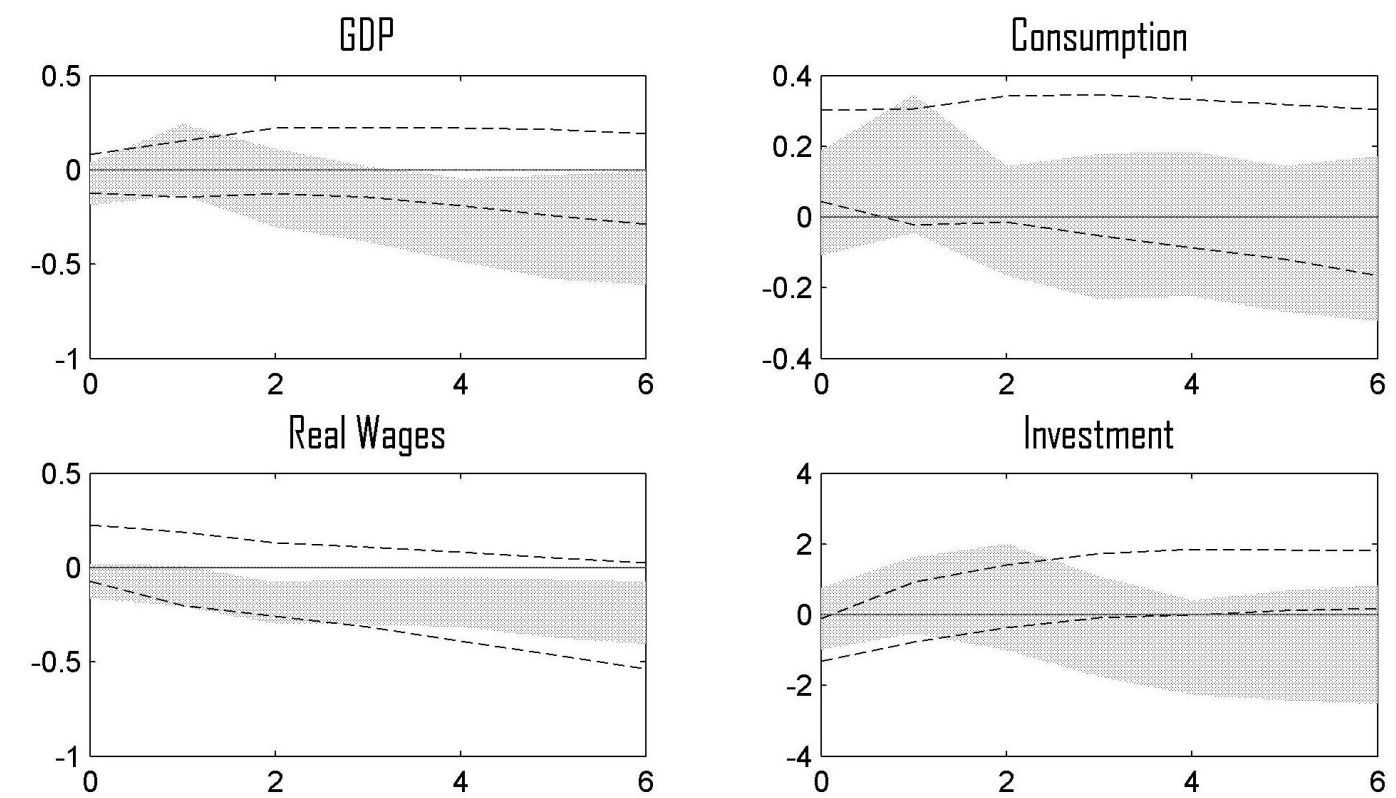

Gov. Spending

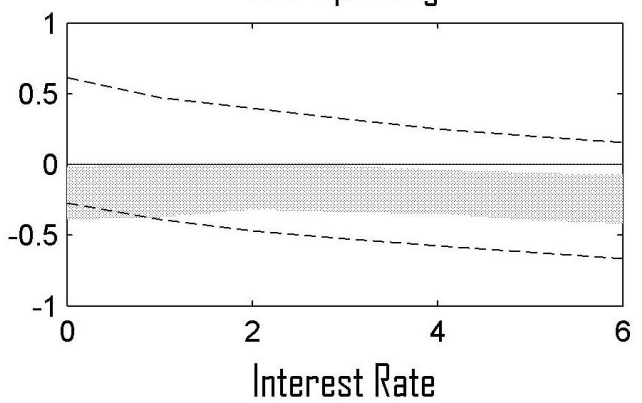

Gav. Revenue
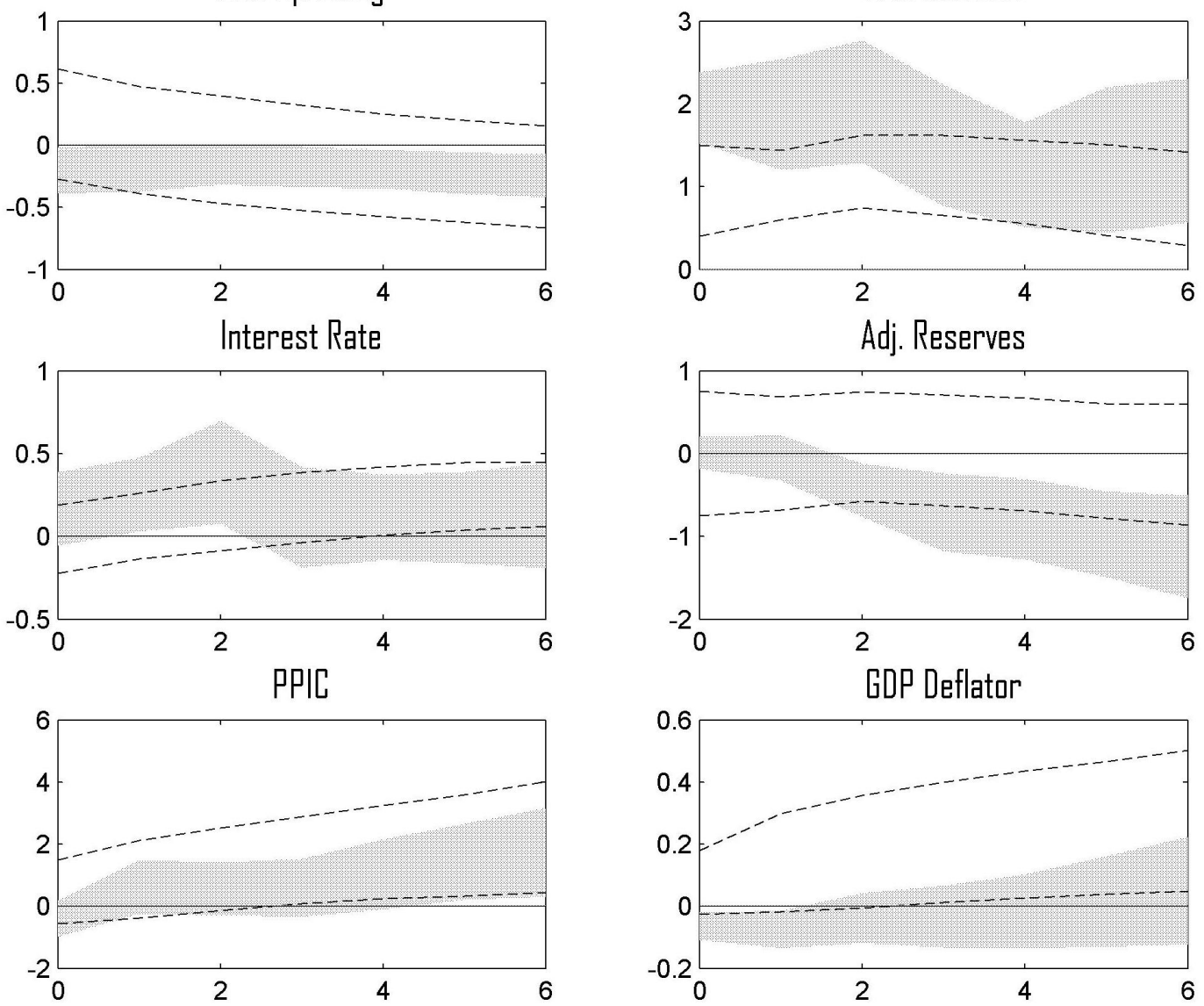

Figure 5: Confidence bounds of the identified sets of the basic government revenue shock. The shaded area indicates the $68 \%$-confidence set in recession, the dashed lines indicate the confidence set in 'normal times'. 


\section{A deficit spending policy scenario}
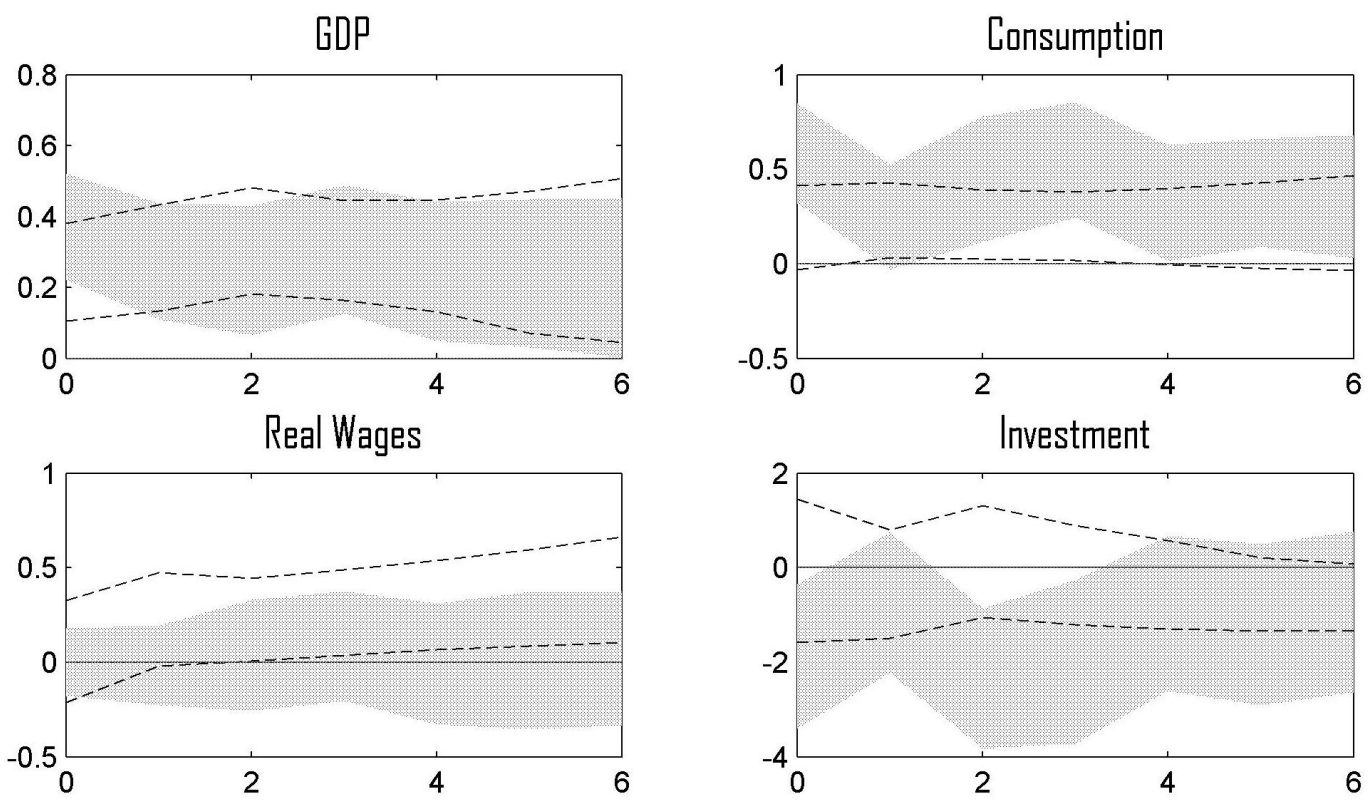

Gov. Spending
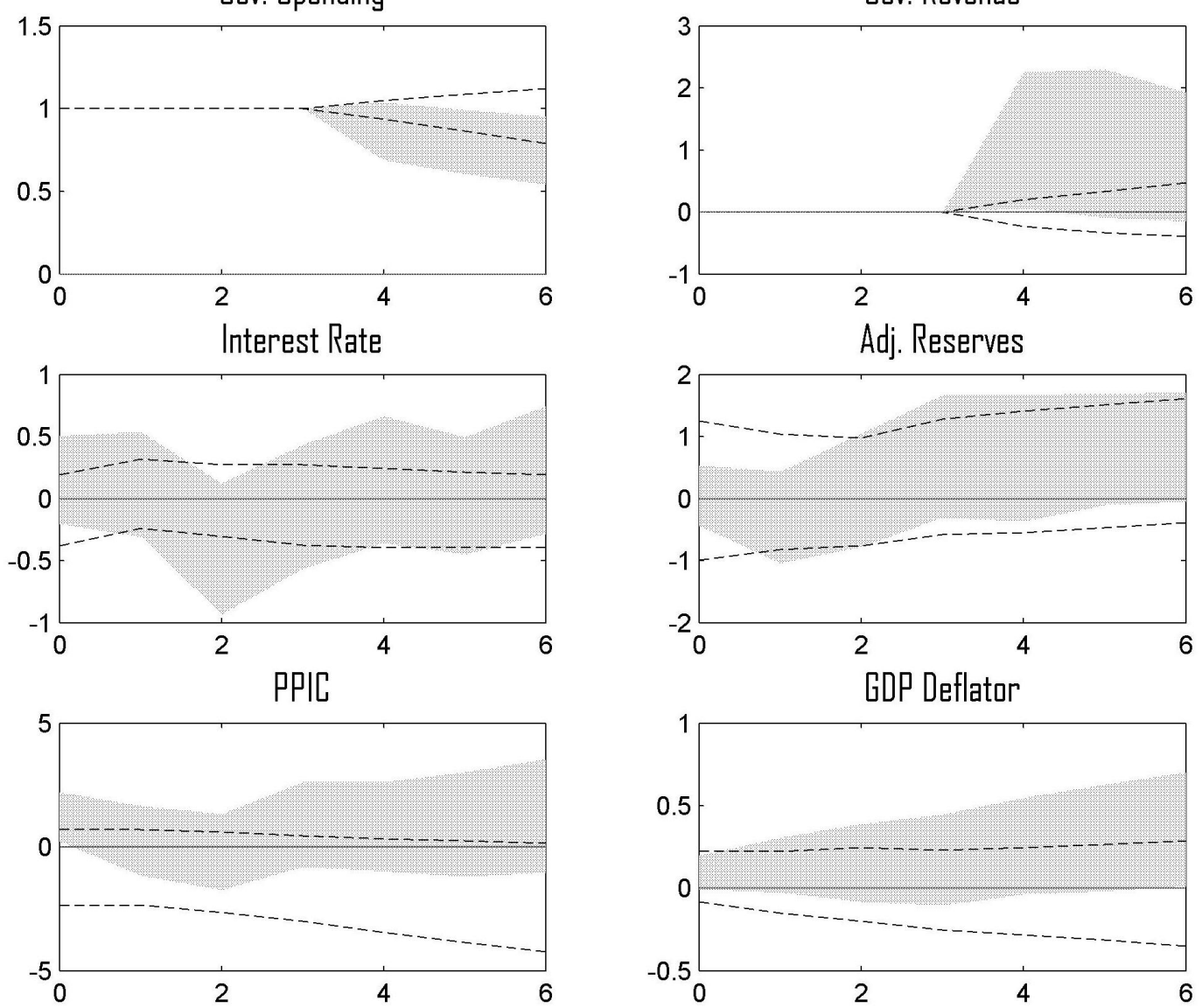

Figure 6: Confidence bounds of the identified sets of the deficit spending shock. The shaded area indicates the $68 \%$-confidence set in recession, the dashed lines indicate the confidence set in 'normal times'. 


\section{A deficit financed tax-cut policy scenario}
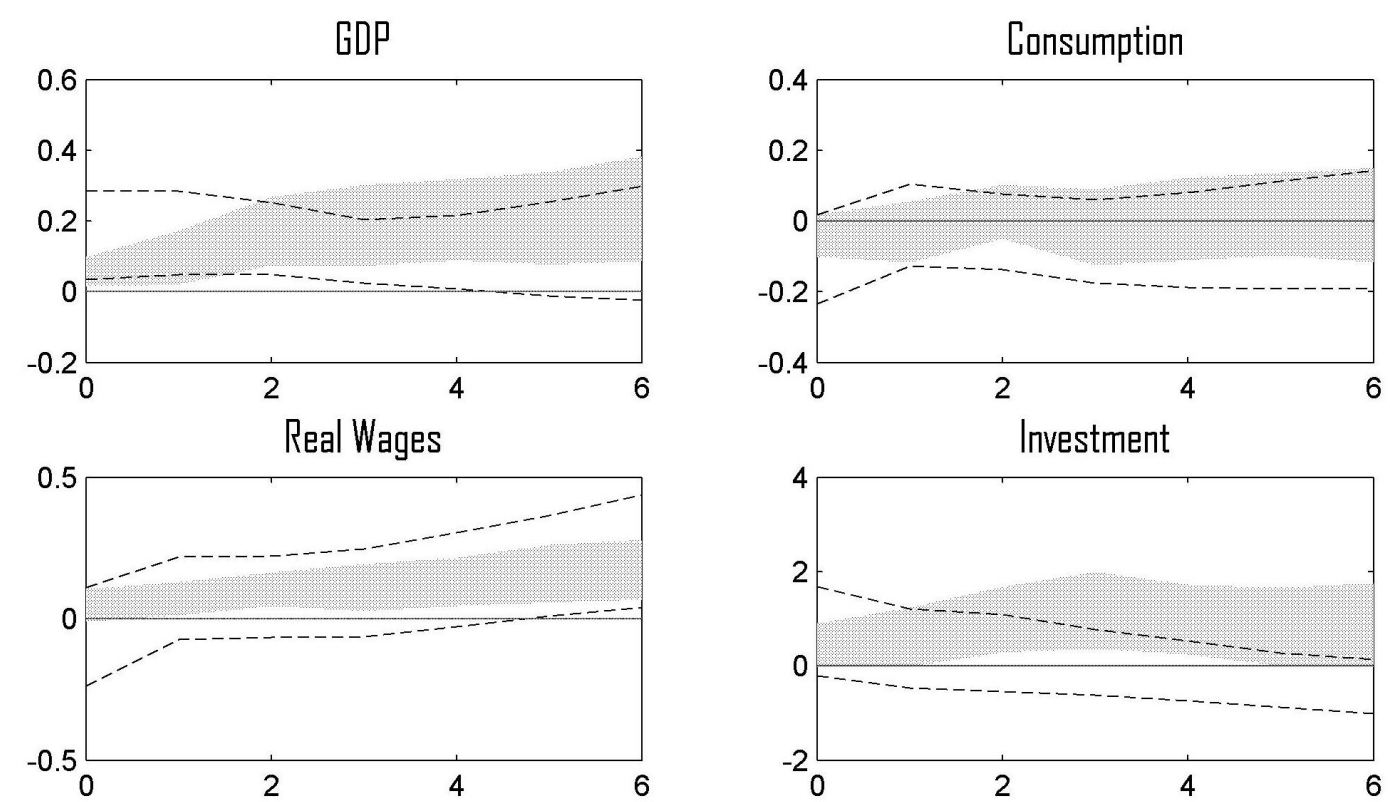

Gov. Spending
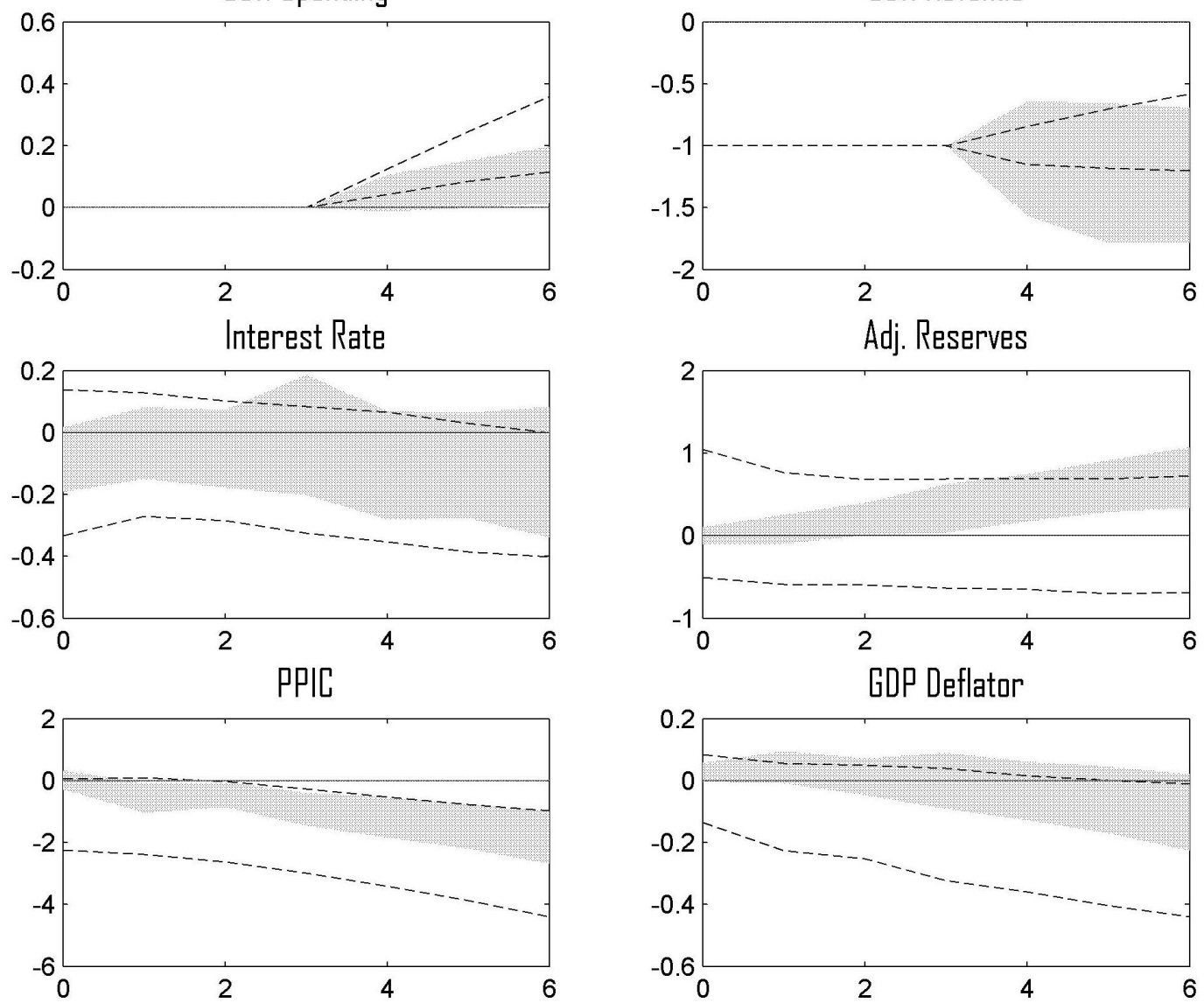

Figure 7: Confidence bounds of the identified sets of the deficit financed tax-cut shock. The shaded area indicates the $68 \%$-confidence set in recession, the dashed lines indicate the confidence set in 'normal times'. 
Present Value Multiplier in Times of Recession
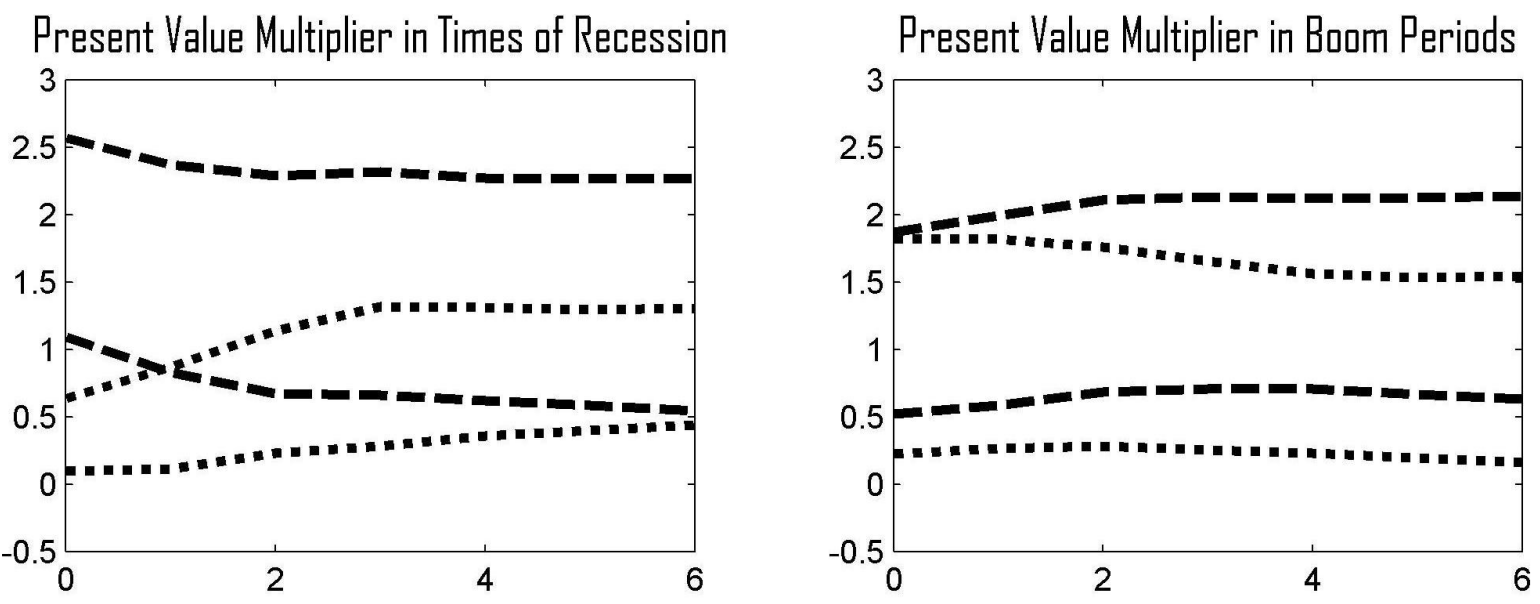

Impact Multiplier in Times of Recession
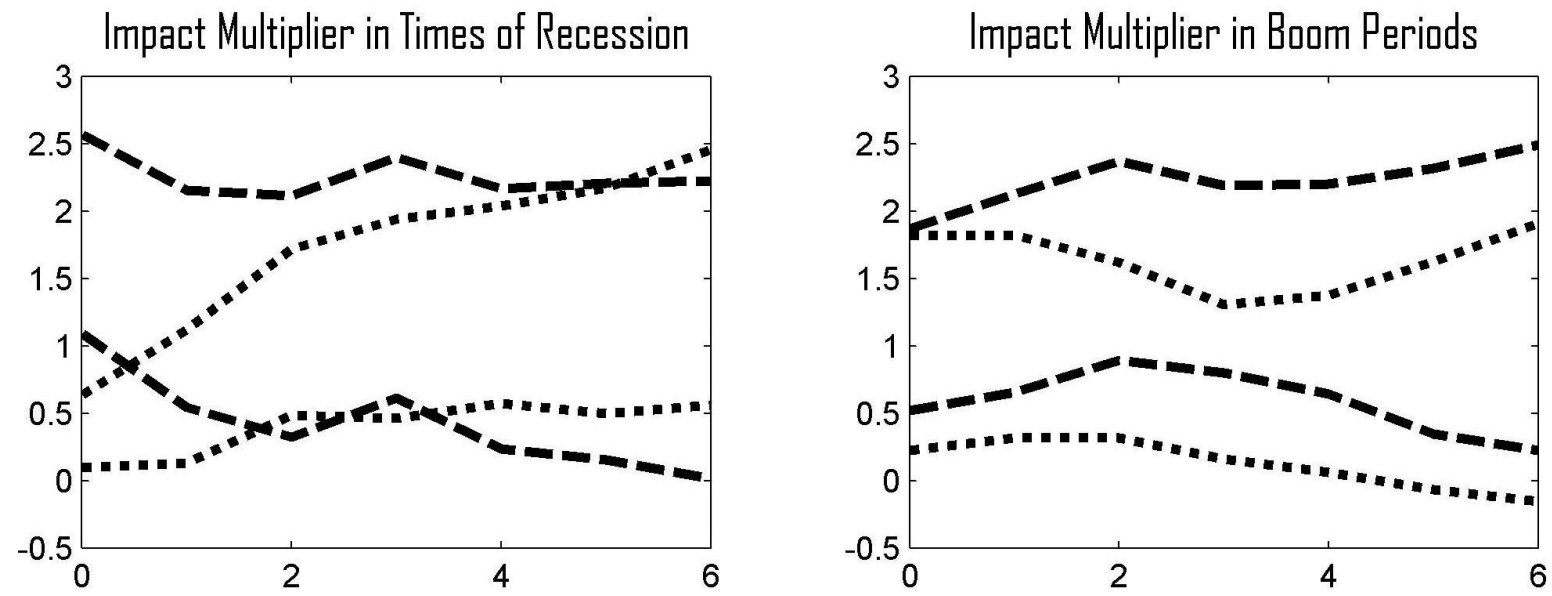

Figure 8: Comparison of $68 \%$ confidence bounds for the impact and present-value multiplier for a deficit spending policy scenario (dashed line) and a deficit financed tax-cut policy scenario (dotted line). 


\section{References}

[1] Andrews, D., Ploberger, W., (1994). "Optimal tests when a nuisance parameter is present only under the alternative," Econometrica 62, 1383-1414.

[2] Bec, F. Rahbek, A., (2004). "Vector Equilibrium Correction Models with Non-Linear Discontinuous Adjustments," Econometrics Journal, Royal Economic Society, vol. 7(2), 628-651.

[3] Benkwitz, A., Lütkepohl, H. Wolters, J., (2001). "Comparison of Bootstrap Confidence Intervals for Impulse Responses of German Monetary Systems," Macroeconomic Dynamics, 5, 81100

[4] Bernanke, B., (1986). "Alternative Explanations of the Money-Income Correlation," in Brunner, K. and Meltzer, A., eds., Real Business Cycles, Real Exchange Rates, and Actual Policies, CarnegieRochester Conference Series on Public Policy, no. 25, Amsterdam, North-Holland.

[5] Blanchard, O. Perotti, R., (2002). "An Empirical Characterization Of The Dynamic Effects of Changes in Government Spending and Taxes on Output," The Quarterly Journal of Economics, MIT Press, 117(4), 1329-1368.

[6] Blanchard, O. Quah, D., (1989). "The Dynamic Effects of Aggregate Demand and Supply Disturbances," American Economic Review, 79, 655-673.

[7] Burnside, C., Eichenbaum, M. Fisher, J., (2004). "Fiscal Shocks and their Consequences," Journal of Economic Theory, Elsevier, 115(1), 89-117. 
[8] Caldara, D. Kamps, C., 2008. "What are the Effects of Fiscal Shocks? A VAR-based Comparative Analysis," Working Paper Series 877, European Central Bank.

[9] Candelon, B., Lieb, L., (2010). "Estimating and Testing for Short-Run Threshold Effects in a Vector Error Correction Framework," mimeo, Maastricht University.

[10] Canova, F. Nicolo, G., (2002). "Monetary Disturbances Matter for Business Fluctuations in the G7," Journal of Monetary Economics, 49, 1131-1159.

[11] Canova, F. Pappa, E., (2007). "Price Differentials in Monetary Unions: The Role of Fiscal Shocks," Economic Journal, 117, 713-737.

[12] Davies, R.B. (1987). "Hypothesis Testing when a Nuisance parameter is Present only under the Alternative," Biometrika, 74 33-43.

[13] Diebold F, Lee J-H, Weinbach G.C. (1999). "Regime Switching with Time-Varying Transition Probabilities," In Business cycles: durations, dynamics and forecasting, Princeton University Press.

[14] Fry, R. PAgan, A. (2010). "Sign Restrictions in Structural Vector Autoregressions: A Critical Review," Journal of Economic Literature, forthcoming.

[15] Gali, J., (1992). "How Well does the IS-LM model fit Postwar U.S. Data?," Quarterly Journal of Economics, 107(2), 709-738.

[16] Gali, J., Lopez-Salido, D. Valles, J., (2007). "Understanding the Effects of Government Spending on Consumption," Journal of the European Economic Association, vol. 5(1), 227-270. 
[17] Giavazzi, F., Jappelli, T. Pagano, M. (2000). "Searching for Non-Linear Effects of Fiscal Policy: Evidence from Industrial and Developing Countries," European Economic Review, 44(7), $1259-1289$.

[18] Gonzalo, J. Pitarakis, J., (2007). "Threshold Effects in Multivariate Error Correction Models," Open Access publications from Universidad Carlos III de Madrid.

[19] Hansen, B. E, (1996). "Inference When a Nuisance Parameter Is not Identified under the Null Hypothesis," Econometrica, 64(2), 413-30,

[20] Hamilton J. (1989). "A New Approach to the Economic Analysis of Nonstationary Time Series and the Business Cycle," Econometrica, 57, 357-384.

[21] Kilian, L. Murphy, D., (2010). "The Role of Inventories and Speculative Trading in the Global Market for Crude Oil," CEPR Discussion Papers 7753.

[22] Lütkepohl, H. Reimers, H., (1992). "Impulse Response Analysis of Cointegrated Systems," Journal of Economic Dynamics and Control, Elsevier, 16(1), 53-78.

[23] LÜtkepohl, H. Saikkonen, P., (1997). "Impulse Response Analysis in Infinite Order Cointegrated Vector Autoregressive Processes," Journal of Econometrics, Elsevier, 81(1), pages 127-157.

[24] Moon, H.R., Schorfheide, F., Granziera, E. Lee, M.,(2009) "Inference for VARs Identified with Sign Restrictions," mimeo, University of Pennsylvania (Prelimnary). 
[25] Mountford, A. Uhlig, H. (2009). "What are the Effects of Fiscal Policy Shocks?," Journal of Applied Econometrics, 24(6), 960-992

[26] Neftci, S., (1984). "Are Economic Time Series Asymmetric over the Business Cycle?," Journal of Political Economy, vol. 92, 307-328.

[27] Perotti R., (1999). "Fiscal Policy In Good Times And Bad," The Quarterly Journal of Economics, 114(4), 1399-1436.

[28] Romer, C. Romer, D., (2010). "The Macroeconomic Effects of Tax Changes: Estimates Based on a new Measure of Fiscal Shocks," American Economic Review, American Economic Association, 100(3), $763-801$.

[29] Saikkonen, P., (1992). "Estimation and Testing of Cointegrated Systems by an Autoregressive Approximation," Econometric Theory, 8, 1-27.

[30] Stewart, G. W., (1980). "The Efficient Generation of Random Orthogonal Matrices with an Application to Condition Estimators," SIAM J. Numer. Anal. 17(3): 403-409.

[31] Tong, H., (1990). "Nonlinear Time Series: A Dynamic System Approach," Clarendon Press, Oxford, UK.

[32] Tsay, R.S. (1998). "Testing and Modeling Multivariate Threshold Models," J. Am. Stat. Assoc., $93,1188-1202$. 